\title{
Luminescent Lanthanide MOFs: A Unique Platform for Chemical Sensing
}

\author{
Shu-Na Zhao ${ }^{1,2}$, Guangbo Wang ${ }^{1}$, Dirk Poelman ${ }^{2}$ (D) and Pascal Van Der Voort ${ }^{1, *(1)}$ \\ 1 Department of Chemistry, Center for Ordered Materials, Organometallics and Catalysis (COMOC), \\ Ghent University, Krijgslaan 281 (S3), 9000 Gent, Belgium; shuna.zhao@Ugent.be (S.-N.Z.); \\ Guangbo.Wang@UGent.be (G.W.) \\ 2 LumiLab, Department of Solid State Sciences, Ghent University, Krijgslaan 281 (S1), 9000 Gent, Belgium; \\ Dirk.Poelman@UGent.be \\ * Correspondence: Pascal.VanDerVoort@UGent.be; Tel.: +32-9-264-44-42
}

Received: 19 March 2018; Accepted: 5 April 2018; Published: 7 April 2018

\begin{abstract}
In recent years, lanthanide metal-organic frameworks (LnMOFs) have developed to be an interesting subclass of MOFs. The combination of the characteristic luminescent properties of Ln ions with the intriguing topological structures of MOFs opens up promising possibilities for the design of LnMOF-based chemical sensors. In this review, we present the most recent developments of LnMOFs as chemical sensors by briefly introducing the general luminescence features of LnMOFs, followed by a comprehensive investigation of the applications of LnMOF sensors for cations, anions, small molecules, nitroaromatic explosives, gases, vapors, $\mathrm{pH}$, and temperature, as well as biomolecules.
\end{abstract}

Keywords: metal-organic frameworks; lanthanide codoping; chemical sensors; ratiometric luminescence sensing

\section{Introduction}

Metal-organic frameworks (MOFs) have attracted extensive attention over the past few decades. They are an emerging class of highly crystalline and porous materials formed by metal ions or metal clusters connected by multitopic organic linkers [1]. Their large surface areas, framework flexibility, and tunable pore surface properties, as well as "tailor-made" framework functionalities empower them to be promising candidates for a diverse range of applications, such as gas separation and sorption [2-4], luminescence [5,6], chemical catalysis [7,8], drug delivery [9], magnetism [10], chemical sensing [11-13], energy storage and conversion [14-16], proton conduction [17,18], and bio-imaging [19].

As a subclass of MOFs, luminescent MOFs possess potential for practical applications because of their explicit environments for luminophores in a crystalline state and characteristic optical performance [20]. Generally, the luminescent properties of MOFs generate from metal components and organic linkers with aromatic or conjugated $\pi$ systems. The metal-ligand charge transfer (MLCT) related luminescence can extend their luminescence functionalities to another dimension. Moreover, some adsorbed guest molecules within MOFs are able to contribute to the luminescent properties. Until now, research on luminescent MOFs has mainly focused on the fundamental luminescent properties of MOFs, and the rational design of tunable luminescent MOFs for light emitting applications [21]. Recently, luminescent MOFs have been proven to be a unique platform for chemical sensing due to their special features, including (i) easily tunable luminescence that can be used as the appropriate sensing signal; (ii) specific functional groups (e.g., Lewis sites and open metal sites) that are able to promote preferred host-guest binding for selective sensing; and (iii) the permanent MOFs' porosity that could concentrate the guest molecules, thereby enhancing detective sensitivity. Numerous luminescent MOF sensors have been developed and reported in the literature for detecting cations [22,23], anions [24,25], 
small molecules [26-28], biological molecules [29,30], explosive chemicals [31-33], vapors [34,35], and $\mathrm{pH}$ [36], as well as temperature [37-39].

Lanthanide MOFs (LnMOFs) have drawn much attention among the luminescent MOFs because of the unique luminescent properties of lanthanide ions, such as long lifetime, characteristic sharp emissions, large Stokes shifts, and high color purity with high quantum yields in the near-infrared and visible regions [40-45]. Additionally, the luminescent properties of lanthanide ions highly depend on the structural details of their coordination environment, offering a unique platform as chemical sensors. The combination of these characteristic luminescent properties of lanthanide ions with the intriguing topological structures of MOFs opens up promising possibilities for developing luminescent materials with special applications.

In this review, we present the most recent developments of LnMOFs as chemical sensors. We begin by briefly introducing the general luminescence features of LnMOFs, followed by a comprehensive investigation of the applications of LnMOF sensors with single or multiple luminescent centers. More specifically, LnMOF sensors for cations, anions, small molecules, nitroaromatic explosives, gases, vapors, $\mathrm{pH}$, and temperature, as well as biomolecules will be discussed in detail in this review.

\section{Luminescent Properties of LnMOFs}

Generally, lanthanide ions $\left(\mathrm{Ln}^{3+}\right)$ are characterized by successive filling of the $4 \mathrm{f}$ orbitals, with electronic configurations of [Xe] $4 \mathrm{f}^{n}$ ( $n=0$ to 14). These electronic configurations generate a rich variety of electronic levels with the number $14 ! / n !(14-n) !$, resulting in interesting optical properties [46-49]. All of the $\mathrm{Ln}^{3+}$, except $\mathrm{La}^{3+}\left(4 \mathrm{f}^{0}\right)$ and $\mathrm{Lu}^{3+}\left(4 \mathrm{f}^{14}\right)$, exhibit luminescent $\mathrm{f}-\mathrm{f}$ emissions, which almost cover the entire spectrum. $\mathrm{Eu}^{3+}, \mathrm{Tb}^{3+}, \mathrm{Sm}^{3+}$, and $\mathrm{Tm}^{3+}$ emit in the visible region with the color red, green, orange, and blue, respectively. $\mathrm{Pr}^{3+}, \mathrm{Nd}^{3+}, \mathrm{Sm}^{3+}, \mathrm{Dy}^{3+}, \mathrm{Ho}^{3+}, \mathrm{Er}^{3+}, \mathrm{Tm}^{3+}$, and $\mathrm{Yb}^{3+}$ show emissions the near-infrared region, while $\mathrm{Ce}^{3+}$ shows a broadband emission from 370 to $410 \mathrm{~nm}$ because of the $5 \mathrm{~d}-4 \mathrm{f}$ transition [50].

Typically, the $4 \mathrm{f}-4 \mathrm{f}$ transitions of $\mathrm{Ln}^{3+}$ are Laporte forbidden due to the $4 \mathrm{f}$ orbitals that are well-shielded by the filled $5 s^{2} 5 p^{6}$ subshells [51]. Consequently, direct photoexcitation of $\mathrm{Ln}^{3+}$ ions rarely produces highly luminescent materials due to the low absorption efficiency of the $4 \mathrm{f}-4 \mathrm{f}$ transitions. This problem can be overcome by the "antenna effect" (Figure 1), which commonly uses a strong absorbing chromophore to sensitize $\mathrm{Ln}^{3+}[52,53]$. The overall process of antenna sensitization involves the following characteristic steps: (i) the organic ligands can absorb light upon excitation; (ii) the excitation energy is then transferred into $\mathrm{Ln}^{3+}$ excited states through intramolecular energy transfer; and (iii) $\mathrm{Ln}^{3+}$ ions undergo a radiative process by characteristic luminescence. This process could effectively increase the luminescence quantum yield of $\mathrm{Ln}^{3+}$ in normal conditions at room temperature. Furthermore, the solvent quenching and self-quenching of $\mathrm{Ln}^{3+}$ ions are almost nullified in LnMOFs due to the separation of $\mathrm{Ln}^{3+}$ ions by organic ligands. Consequently, LnMOFs exhibit strong luminescence and can be utilized as chemical sensors.

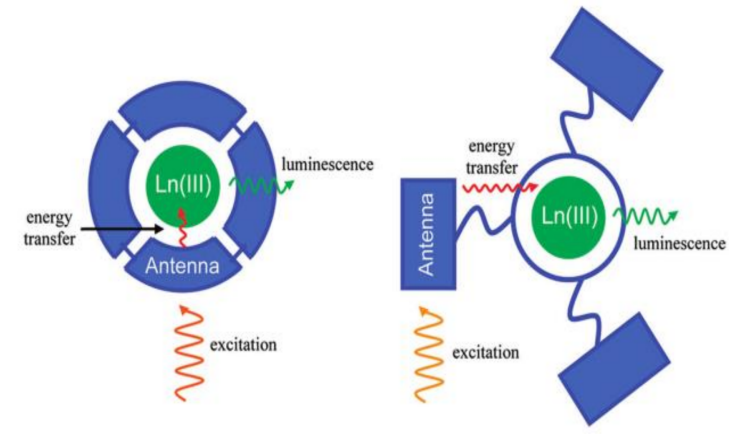

Figure 1. The antenna effect for lanthanide(III) ( $\mathrm{Ln}(\mathrm{III}))$ sensitization, illustrated using the chromophoric chelate (right) and pendant chromophore (left) ligand designs. Reprinted with permission from [48]. Copyright 2009, American Chemical Society. 
There are two other types of electronic transitions of $\mathrm{Ln}^{3+}$ ions: broad charge-transfer transitions (ligand-metal charge transfer (LMCT) and metal-ligand charge transfer (MLCT)) and broad 4f-5d transitions. They usually occur with high energies, resulting in rare observation in coordination compounds. However, the excitation energy of $\mathrm{Sm}^{3+}, \mathrm{Eu}^{3+}$, and $\mathrm{Yb}^{3+}$ can be transferred from an LMCT state to their $4 \mathrm{f}$ levels when the LMCT state lies at a high enough energy level. It is of great importance to investigate the numerous energy transfer processes for well-tuning the luminescent properties of LnMOFs.

The luminescence of $\mathrm{Ln}^{3+}$ ions is only possible from resonance levels, such as ${ }^{5} \mathrm{D}_{0}$ for $\mathrm{Eu}^{3+},{ }^{5} \mathrm{D}_{4}$ for $\mathrm{Tb}^{3+}$, and ${ }^{2} \mathrm{~F}_{5 / 2}$ for $\mathrm{Yb}^{3+}$. The energies of resonance levels of $\mathrm{Eu}^{3+}\left({ }^{5} \mathrm{D}_{0}\right), \mathrm{Tb}^{3+}\left({ }^{5} \mathrm{D}_{4}\right)$, and $\mathrm{Yb}^{3+}\left({ }^{2} \mathrm{~F}_{5 / 2}\right)$ lie at 17,250,20,430, and 10,200 $\mathrm{cm}^{-1}$, respectively [54]. If the $\mathrm{Ln}^{3+}$ ions are excited to a nonresonance level, the excitation energy is dissipated through a nonradiative process until a resonance level is reached. Therefore, the lowest triplet state of the organic ligands in LnMOFs must be located at an energy level nearly equal to or above the resonance level of the $\mathrm{Ln}^{3+}$ ions. If the energy difference between the organic linkers and $\mathrm{Ln}^{3+}$ ions is too small, a thermally activated energy back-transfer will occur. On the other hand, large energy differences may lead to slower energy transfer rates. The energy of the triplet state must be elaborately tuned to maximize the transfer and minimize the back-transfer. Thus, the rational design of suitable organic ligands with the appropriate energy level is of great significance for the synthesis of LnMOFs with the desired luminescent properties.

\section{LnMOFs for Chemical Sensing}

LnMOFs have been widely studied in various sensor applications owing to their inherent porosity and the particular luminescent properties of $\mathrm{Ln}^{3+}$ ions. Most of the $\mathrm{LnMOF}$ sensors show luminescence intensity changes, including luminescence enhancement (turn-on response) and quenching (turn-off response) upon recognition of the analytes. $\mathrm{Eu}^{3+}$ and $\mathrm{Tb}^{3+}$ are commonly used as luminescent centers in LnMOF sensors because of their strong, characteristic red emission at around $614 \mathrm{~nm}$ and green emission at around $541 \mathrm{~nm}$, respectively [55]. LnMOFs succeed in sensing ionic species, small molecules, explosive chemicals, and $\mathrm{pH}$, as well as temperature. In addition, the inherent structural and chemical features of LnMOFs make them considerably useful in biosensing and bioimaging applications [56]. In the remainder of this section, recent developments of LnMOFs for chemical sensing will be discussed in detail.

\subsection{LnMOFs for Cation Sensing}

Sensing and detecting metal ions is of great significance in environmental and ecological systems. Some transition-metal cations, such as $\mathrm{Cu}^{2+}, \mathrm{Fe}^{2+}, \mathrm{Fe}^{3+}$, and $\mathrm{Zn}^{2+}$, are essential in biological metabolism. The excess or deficiency of these metal cations can cause various diseases, such as Alzheimer's disease, Wilson's disease, anemia, mental decline, etc. [57-60]. $\mathrm{Hg}^{2+}, \mathrm{Pb}^{2+}$, and $\mathrm{Cd}^{2+}$ are well-known toxic metal ions that can give rise to serious damage to the human body and environment [61,62]. Therefore, the design and preparation of efficient and straightforward metal ion probes are urgently needed.

In 2009, Chen et al. reported a new LnMOF $\left[\mathrm{Eu}(\mathrm{PDC})_{1.5}(\mathrm{DMF})\right](\mathrm{DMF})_{0.5}\left(\mathrm{H}_{2} \mathrm{O}\right)_{0.5}(\mathrm{PDC}=$ pyridine-3,5-dicarboxylate, $\mathrm{DMF}=\mathrm{N}^{\prime} \mathrm{N}$-dimethylformamide) with Lewis basic pyridyl sites for sensing $\mathrm{Cu}^{2+}$ ions [63]. The desolated MOF Eu(PDC $)_{1.5}$ can selectively detect $\mathrm{Co}^{2+}$ and especially $\mathrm{Cu}^{2+}$ among other metal ions via a turn-off response. The authors hypothesized that the antenna efficiency of the PDC organic ligands was reduced by the binding of the pyridyl nitrogen atoms to $\mathrm{Cu}^{2+}$ or $\mathrm{Co}^{2+}$, resulting in luminescence quenching. From then on, many LnMOF sensors with unsaturated Lewis basic sites have been synthesized based on this mechanism for detecting metal ions [64-68]. Recently, Yan and coworkers developed a FAM-ssDNA and Eu ${ }^{3+} @ B i o-M O F-1$ for sensing $\mathrm{Cu}^{2+}$ in aqueous solutions [69]. This luminescent hybrid material can simultaneously exhibit FAM and $\mathrm{Eu}^{3+}$ emissions by varying the ratio of Eu ${ }^{3+} @$ Bio-MOF-1 and FAM-ssDNA. $\mathrm{Cu}^{2+}$ can quench FAM emission, while enhancing the luminescence intensity of $\mathrm{Eu}^{3+}$ (Figure 2). The mechanism behind this is possibly based on the interaction of $\mathrm{Cu}^{2+}$ and ssDNA. 

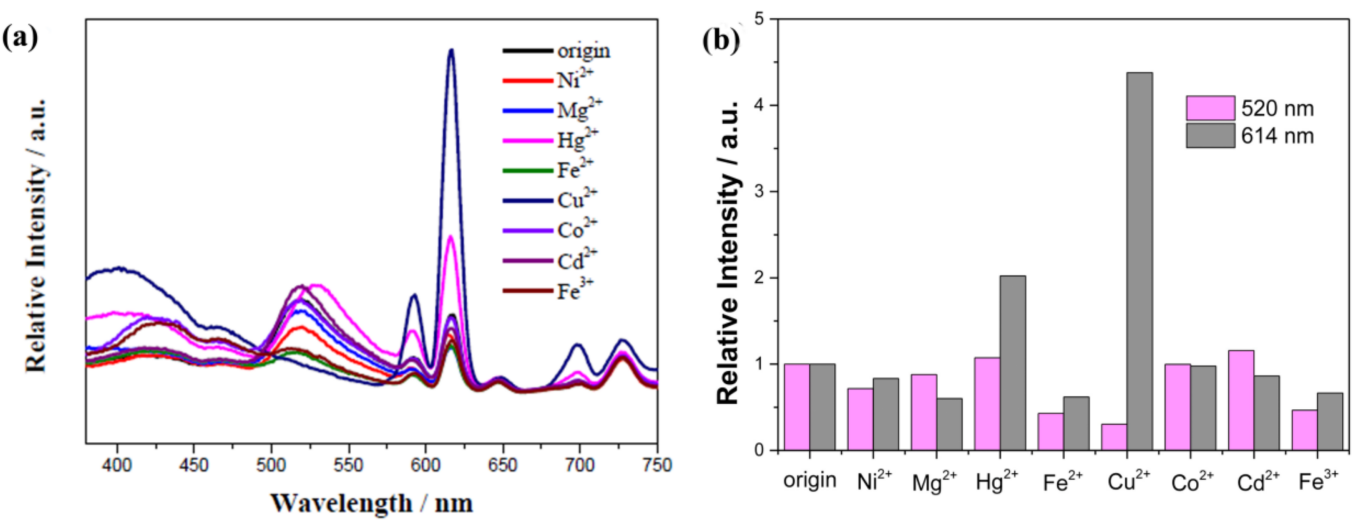

Figure 2. (a) PL spectra of FAM-ssDNA and Eu ${ }^{3+} @ B i o-M O F-1$ dispersed into aqueous solutions of various metal ions with the concentration of $10^{-5} \mathrm{~mol} / \mathrm{L}$ when excited at $323 \mathrm{~nm}$; (b) Relative luminescence intensity of FAM at $520 \mathrm{~nm}$ and $\mathrm{Eu}^{3+}$ at $614 \mathrm{~nm}$. Reprinted with permission from [69]. Copyright 2017 Elsevier B.V., New York, NY, USA.

Additionally, $\mathrm{Fe}^{3+}$ detection was achieved by Zheng et al. with $\left[\mathrm{Eu}\left(\mathrm{L}_{1}\right)(\mathrm{BPDC})_{0.5}\left(\mathrm{NO}_{3}\right)\right] \cdot \mathrm{H}_{3} \mathrm{O}$ $\left(\mathrm{H}_{2} \mathrm{~L}_{1}=2,5\right.$-di(pyridin-4-yl)terephthalic acid, BPDC = biphenyl-4,4'-dicarboxylic acid) based on an excellent luminescence turn-off response with a remarkable detection limit $\left(5 \times 10^{-7} \mathrm{~mol} / \mathrm{L}\right)$ over various other metal cations, including $\mathrm{Na}^{+}, \mathrm{K}^{+}, \mathrm{Cu}^{2+}, \mathrm{Al}^{3+}, \mathrm{Mg}^{2+}, \mathrm{Cr}^{3+}, \mathrm{Zn}^{2+}$, and $\mathrm{Co}^{2+}$ [70]. Sun and coworkers reported an anionic EuMOF, $\left[\mathrm{H}_{2} \mathrm{~N}\left(\mathrm{CH}_{3}\right)_{2}\right]\left[\mathrm{Eu}\left(\mathrm{H}_{2} \mathrm{O}\right)_{2}(\mathrm{BTMIPA})\right] \cdot 2 \mathrm{H}_{2} \mathrm{O}\left(\mathrm{H}_{4} \mathrm{BTMIPA}=\right.$ 5,5'-methylenebis(2,4,6-trimethylisophthalic acid)) with $\left[\mathrm{H}_{2} \mathrm{~N}\left(\mathrm{CH}_{3}\right)_{2}\right]^{+}$cations in the tubular channels of the anionic frameworks, which exhibited luminescence quenching for $\mathrm{Fe}^{3+}$ and luminescence enhancement for $\mathrm{Al}^{3+}$ via ion-exchange between $\left[\mathrm{H}_{2} \mathrm{~N}\left(\mathrm{CH}_{3}\right)_{2}\right]^{+}$cations and metal cations [71].

Tan et al. prepared adenine-based lanthanide coordination polymer nanoparticles (CPNPs), consisting of adenine (Ad), a $\mathrm{Tb}^{3+}$ ion, and dipicolinic acid (DPA). It showed a turn-on luminescence response for $\mathrm{Hg}^{2+}$ in aqueous solutions [72]. Due to the photoinduced electron transfer (PET) process, the Ad can transfer energy to the DPA and simultaneously prevent intramolecular energy transfer from DPA to $\mathrm{Tb}^{3+}$, leading to the luminescence quenching of the CPNPs (Figure 3a). However, significantly enhanced luminescence (approximately fivefold) was observed in the CPNPs because of the suppression of the PET process from Ad to DPA by $\mathrm{Hg}^{2+}$, which was further confirmed by Fourier-transform infrared spectroscopy (FTIR) and lifetime study (Figure 3b). This $\mathrm{Hg}^{2+}$ nanosensor also showed superior selectivity and exceptionally high sensitivity up to the detection limit of $0.2 \mathrm{nM}$ and can be used in biosensing and imaging. Li and coworkers reported a EuMOF $\left(\left[\mathrm{Eu}_{2}(\mathrm{FDC})_{3} \mathrm{DMA}\left(\mathrm{H}_{2} \mathrm{O}\right)_{3}\right] \cdot \mathrm{DMA} \cdot 4.5 \mathrm{H}_{2} \mathrm{O}, \mathrm{H}_{2} \mathrm{FDC}=\right.$ 9,9-dimethyl-2,7-fluorenedicarboxylic acid,DMA = dimethylacetamide) for sensing $\mathrm{Pb}^{2+}$ in aqueous solutions through luminescence enhancement [73]. Another luminescence sensor for detecting $\mathrm{Pb}^{2+}$ based on a millimeter-sized TbMOF $\left\{\left[\mathrm{Tb}\left(\mathrm{L}_{2}\right)\left(\mathrm{H}_{2} \mathrm{O}\right)_{5}\right]_{n}\right.$. solvents $\mathrm{H}_{2} \mathrm{~L}_{2}-=3$, 5-dicarboxy-phenol anion ligand $\}$ was reported by Ji and coworkers [74]. It is the first high-efficiency MOF-based luminescence sensor for $\mathrm{Pb}^{2+}$ at a very low concentration and with the detection limit up to $10^{-7} \mathrm{M}$. A robust MOF, Sm-MIL-61(MIL-61 = $\mathrm{Ga}(\mathrm{OH})(\mathrm{btec}) \cdot 0.5 \mathrm{H}_{2} \mathrm{O}, \mathrm{H}_{4}$ btec $=$ Pyromellitic acid $)$, was designed as an $\mathrm{Ag}^{+}$sensor in aqueous solutions with high efficiency and selectivity (Figure 3c,d). The luminescence enhancement was due to a more efficient energy transfer from organic linkers to $\mathrm{Sm}^{3+}$ evoked by $\mathrm{Ag}^{+}$(Figure 3e) [75]. 
(a)

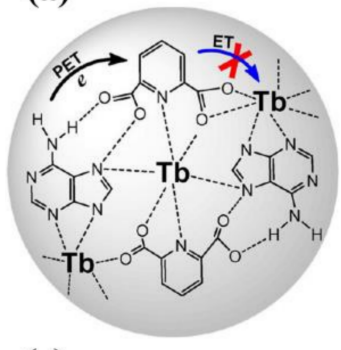

(c)

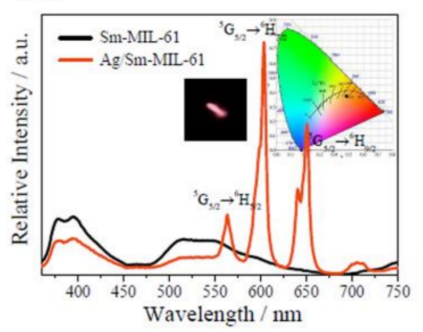

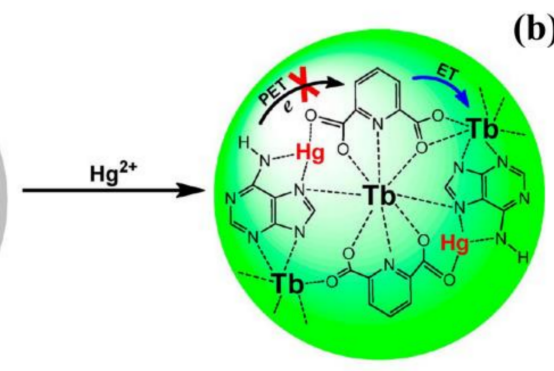

(d)

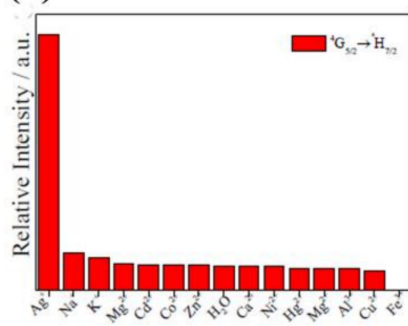

(b)

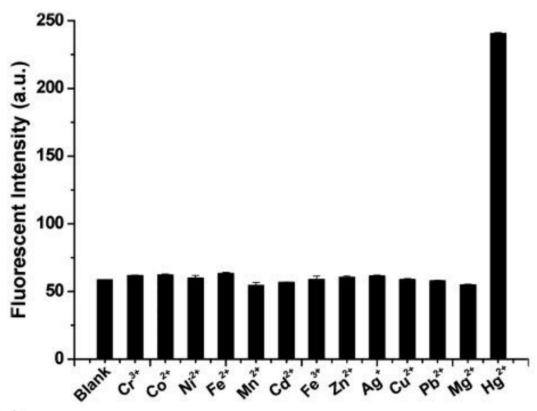

(e)

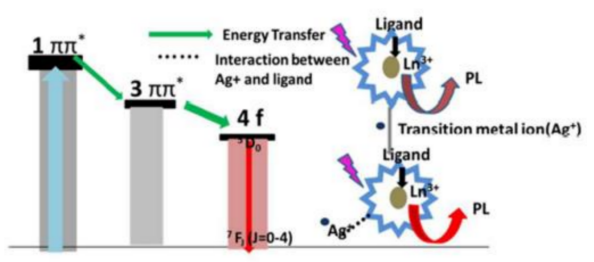

Figure 3. (a) $\mathrm{Ad} / \mathrm{Tb} / \mathrm{DPA}$ coordination polymer nanoparticles (CPNPs) for sensing of $\mathrm{Hg}^{2+}$ by photoinduced electron (PET) transfer; (b) Effect of various metal ions $(1 \mu \mathrm{M})$ on the fluorescence intensity of $\mathrm{Ad} / \mathrm{Tb} / \mathrm{DPA}$ CPNPs at $545 \mathrm{~nm}$. Reprinted with permission from [72]. Copyright 2012, American Chemical Society; (c) PL spectra of Sm-MIL-61 (black line) and Ag/Sm-MIL-61 (orange red line) when excited at $314 \mathrm{~nm}$, the inset shows the CIE chromaticity diagram of Ag/Sm-MIL-61 (x: 0.4804 $\mathrm{y}$ : 0.3823) and corresponding photoluminescence color image under UV-] light irradiation at $314 \mathrm{~nm}$; (d) The relative intensities of ${ }^{4} \mathrm{G}_{5 / 2} \rightarrow{ }^{6} \mathrm{H}_{7 / 2}$ at $603 \mathrm{~nm}$ upon Sm-MIL-61 in the presence of different metal ions; (e) Schematic illustration for the energy transfer from ligand to $\mathrm{Ln}^{3+}$ center. Reprinted with permission from [75]. Copyright 2017, The Royal Society of Chemistry.

\subsection{LnMOFs for Anion Sensing}

Various anions, such as halogen ions $\mathrm{SO}_{4}{ }^{2-}, \mathrm{PO}_{4}{ }^{3-}$, and $\mathrm{CN}^{-}$, are fundamental in environmental and biological systems [76]. Therefore, the sensing of such anions is a remarkably interesting topic to investigate. In recent years, LnMOF-based sensors have been successfully utilized for sensing inorganic anions [77-80]. Chen and coworkers synthesized a TbMOF [Tb(BTC).G] (BTC = benzene-1,3,5tricarboxylate, $\mathrm{G}=$ guest solvent) with $\mathrm{OH}$ groups in the terminal solvents [78]. This TbMOF showed a fourfold luminescence enhancement in the presence of $\mathrm{F}^{-}$, suggesting that this porous luminescent $\mathrm{MOF}$ is a promising candidate for sensing $\mathrm{F}^{-}$(Figure 4a). The possible mechanism of luminescence enhancement by $\mathrm{F}^{-}$ions lies in the stronger hydrogen bonding interactions between the $\mathrm{F}^{-}$ion and the terminal methanol molecules that can restrict the stretching of the $\mathrm{OH}$ bond and thus reduce its quenching effect. The turn-off detection for $\mathrm{F}^{-}$was achieved by Zhou and coworkers using an isostructural-doped LnMOF, $\left[\mathrm{Eu}_{2 x} \mathrm{~Tb}_{2(1-\mathrm{x})}(\mathrm{BPDC})(\mathrm{BDC})_{2}\left(\mathrm{H}_{2} \mathrm{O}\right)_{2}\right]_{n}\left(\mathrm{H}_{2} \mathrm{BPDC}=\right.$ 2,2'-bipyridine-3,3'-dicarboxylic acid, $\mathrm{H}_{2} \mathrm{BDC}=1,4$-benzenedicarboxylic acid) [79]. The emission intensity of this codoped LnMOF reduced to almost zero in the presence of $\mathrm{F}^{-}$in aqueous solutions, while the emission intensities showed no change in the presence of $\mathrm{Cl}^{-}, \mathrm{Br}^{-}$, or $\mathrm{I}^{-}$. The authors speculated that the $\mathrm{F}^{-}$with smaller radii were trapped more easily in the MOF cavities than the other halogen anions, resulting in luminescence quenching. Shi et al. prepared two cationic hetero MOFs, $\left[\mathrm{Ln}_{2} \mathrm{Zn}\left(\mathrm{L}_{3}\right)_{3}\left(\mathrm{H}_{2} \mathrm{O}\right)_{4}\right]\left(\mathrm{NO}_{3}\right)_{2} \cdot 12 \mathrm{H}_{2} \mathrm{O}_{\mathrm{n}}\left(\mathrm{Ln}=\mathrm{Eu}\right.$ and $\mathrm{Tb}, \mathrm{L}_{3}=4,4^{\prime}$-dicarboxylate-2,2'-dipyridine anion) for selective and reversible $\mathrm{I}^{-}$detection in aqueous solutions [80]. $\mathrm{I}^{-}$ions can quench the luminescence of these two cationic MOFs with a fast response time (10 s) and low detection limit $(0.001 \mathrm{ppm})$. It is believed that $\mathrm{I}_{3}{ }^{-}$ions are formed by the oxidation of $\mathrm{I}^{-}$ions with the assistance of MOFs. They block the LMCT process by absorbing the excitation light, thus causing luminescence quenching. 
(a)

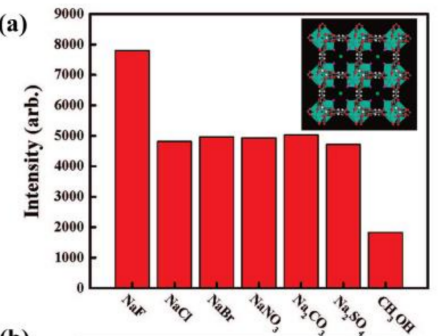

(b)

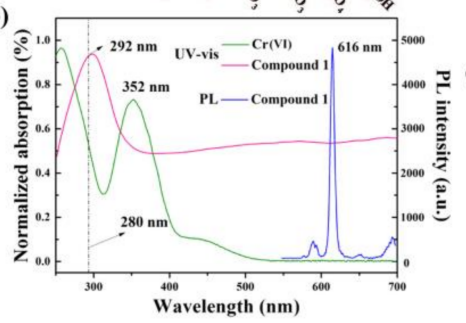

(c)

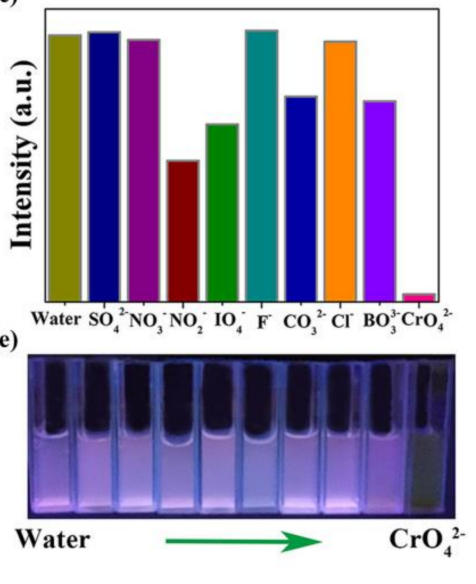

(d)
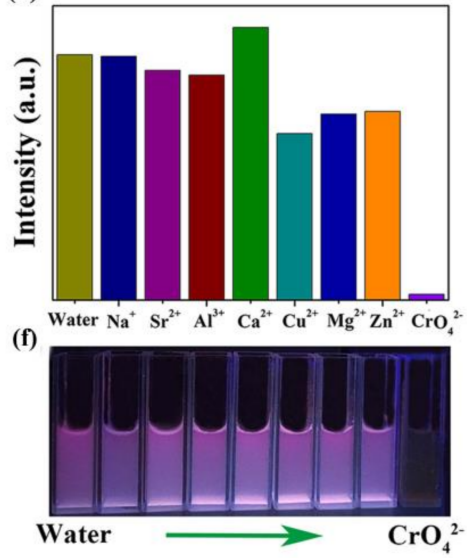

Figure 4. (a) ${ }^{5} \mathrm{D}_{4} \rightarrow{ }^{7} \mathrm{~F}_{5}$ transition intensities of $[\mathrm{Tb}(\mathrm{BTC}) \cdot \mathrm{G}]$ activated in different types of $10^{-2} \mathrm{M} \mathrm{NaX}$ and $\mathrm{Na}_{2} \mathrm{X}$ methanol solution (excited and monitored at 353 and $548 \mathrm{~nm}$, respectively). The insert figure is the single crystal $X$-ray structure of $[\mathrm{Tb}(\mathrm{BTC}) \cdot \mathrm{G}]$ activated in methanol containing NaF with the model of fluoride (green) at the center of the channel involving its hydrogen-bonding interaction with terminal methanol molecules (methanol oxygen, purple; the methyl group from methanol is omitted for clarity). Reprinted with permission from [78]. Copyright 2008, American Chemical Society. (b) Luminescence spectrum and UV-vis absorption spectra. (c,d) Luminescence intensity of ${ }^{5} \mathrm{D}_{0} \rightarrow{ }^{7} \mathrm{~F}_{2}$ of Eu ${ }^{3+}$ at $616 \mathrm{~nm}$ dispersed in different aqueous solutions of various anions and cations. (e) Luminescence in different anion solutions (excited at $365 \mathrm{~nm}$ ), corresponding to figure (c). (f) Luminescence in different cation solutions (excited at $365 \mathrm{~nm}$ ), corresponding to figure (d). Reprinted with permission from [81]. Copyright 2017, American Chemical Society.

Chromium is extensively used in various industrial processes causing $\mathrm{Cr}(\mathrm{VI})$ anions $\left(\mathrm{CrO}_{4}{ }^{2-}\right.$ and $\mathrm{Cr}_{2} \mathrm{O}_{7}{ }^{2-}$ ) to often be present in all kinds of industrial wastewater It is one of the most prevalent, toxic heavy-metal ions of which excess intake can cause serious protein and DNA disruption, as well as damage the human enzyme system [82]. The detection of $\mathrm{Cr}(\mathrm{VI})$ anions was realized through a cationic EuMOF $\left[\mathrm{Eu}_{7}(\mathrm{mtb})_{5}\left(\mathrm{H}_{2} \mathrm{O}\right)_{16}\right] \cdot \mathrm{NO}_{3} \cdot 8 \mathrm{DMA} \cdot 18 \mathrm{H}_{2} \mathrm{O}\left(\mathrm{H}_{4} \mathrm{mtb}=4\right.$-[tris(4-carboxyphenyl)methyl]benzoic acid) with a luminescence turn-off response [81]. The $\mathrm{Cr}(\mathrm{VI})$ anions can absorb the excitation light and hinder the energy absorption of the EuMOF, resulting in luminescence quenching (Figure $4 \mathrm{~b}-\mathrm{f}$ ). This highly stable EuMOF sensor with excellent sensitivity and selectivity can also be utilized in real environmental conditions, such as lake water and sea water, suggesting the possible application of MOF chemical sensors in environmental fields. In another study, Li et al. synthesized a EuMOF [Eu(ipbp $\left.)_{2}\left(\mathrm{H}_{2} \mathrm{O}\right)_{3}\right] \cdot \mathrm{Br} \cdot 6 \mathrm{H}_{2} \mathrm{O}\left(\mathrm{H}_{2} \mathrm{ipbpBr}=1\right.$-(3,5-dicarboxyphenyl)-4,4'-bipyridinium bromide) for the selective detection of $\mathrm{Cr}_{2} \mathrm{O}_{7}{ }^{2-}$ and $\mathrm{CrO}_{4}{ }^{2-}$ anions with $\mathrm{K}_{\mathrm{sv}}$ of $8.98 \times 10^{3} \mathrm{M}^{-1}$ and $7.08 \times 10^{3} \mathrm{M}^{-1}$, respectively [83].

The commonly used strong oxidant, $\mathrm{MnO}_{4}{ }^{-}$, causes serious damage to the environment and human health. A stable luminescence sensor for $\mathrm{MnO}_{4}{ }^{-}$was designed by Yan and coworkers using an In-MOF supporter encapsulated with $\mathrm{Eu}^{3+}$ ions [24]. Upon the addition of $\mathrm{MnO}_{4}{ }^{-}$, the luminescence of In-MOF-Eu was quenched to dark, corresponding to the competition of $\mathrm{MnO}_{4}{ }^{-}$with the organic linkers for absorption of excitation light. Moreover, the color of the MOF-based fluorescence test paper can be observed to go from red to black by the naked eye under UV light irradiation when immersed in different $\mathrm{MnO}_{4}{ }^{-}$concentrations. $\mathrm{Li}$ and coworkers utilized a heterometallic alkaline earth-lanthanide MOF $\left\{\left[\mathrm{Ba}_{3} \mathrm{La}_{0.5}\left(\mu_{3}-\mathrm{L}\right)_{2.5}\left(\mathrm{H}_{2} \mathrm{O}\right)_{3}(\mathrm{DMF})\right] \cdot(3 \mathrm{DMF})\right\}_{\mathrm{n}}\left(\mathrm{H}_{3} \mathrm{~L}_{4}=\right.$ p-terphenyl-3,4",5-tricarboxylic acid) to detect $\mathrm{MnO}_{4}{ }^{-}$with significant quenching over other anions, such as $\mathrm{PO}_{4}{ }^{3-}, \mathrm{Cl}^{-}, \mathrm{SiF}_{6}{ }^{2-}, \mathrm{CO}_{3}{ }^{2-}$, $\mathrm{HCO}_{3}{ }^{-}, \mathrm{BF}_{4}{ }^{-}, \mathrm{NO}_{3}{ }^{-}, \mathrm{Ac}^{-}, \mathrm{SCN}^{-}, \mathrm{SO}_{4}{ }^{2-}, \mathrm{Br}^{-}, \mathrm{I}^{-}, \mathrm{F}^{-}, \mathrm{IO}_{3}^{-}, \mathrm{BrO}_{3}^{-}$, and $\mathrm{ClO}_{4}{ }^{2-}$ [84]. This probe 
exhibited high selectivity and sensitivity for $\mathrm{MnO}_{4}{ }^{-}$ions with high quench efficiency constants $\mathrm{K}_{\mathrm{sv}}=7.73 \times 10^{3} \mathrm{M}^{-1}$, as well as a low fluorescence-detection limit $(0.28 \mu \mathrm{M}(\mathrm{S} / \mathrm{N}=3))$.

$\mathrm{PO}_{4}{ }^{3-}$ ions are also a type of pollutant anion that can cause water eutrophication and serious pollution in aquatic ecosystems [85]. A luminescent TbMOF TbNTA $\cdot \mathrm{H}_{2} \mathrm{O}$ (NTA = nitrilotriacetate) for sensing $\mathrm{PO}_{4}{ }^{3-}$ ions is provided by Qian and coworkers [86]. The luminescence intensity of TbNTA $\cdot \mathrm{H}_{2} \mathrm{O}$ quenched significantly in the presence of $\mathrm{PO}_{4}{ }^{3-}$, while it showed almost no change upon exposure to $\mathrm{F}^{-}, \mathrm{Cl}^{-}, \mathrm{Br}^{-}, \mathrm{I}^{-}, \mathrm{NO}_{3}{ }^{-}, \mathrm{NO}_{2}{ }^{-}, \mathrm{HCO}_{3}{ }^{-}, \mathrm{CO}_{2}{ }^{2-}$, or $\mathrm{SO}_{4}{ }^{2-}$ (Figure 5a). They further discussed possible sensing mechanisms based on the matching degree of $\mathrm{TbNTA} \cdot \mathrm{H}_{2} \mathrm{O}$ with different anions. The $\mathrm{Tb}-\mathrm{O}$ bond may dilute the energy that transferred to $\mathrm{Tb}^{3+}$ via non-radioactive relaxation after incorporating $\mathrm{PO}_{4}{ }^{3-}$ into TbNTA. $\mathrm{H}_{2} \mathrm{O}$ (Figure $5 \mathrm{~b}$ ). Another $\mathrm{PO}_{4}{ }^{3-}$ probe was achieved by Zhao and coworkers using a regenerable EuMOF $\left\{\left[\mathrm{Eu}_{1.5}(\mathrm{BTB})_{1.5}\left(\mathrm{H}_{2} \mathrm{O}\right)\right] \cdot 3 \mathrm{DMF}\right\}_{\mathrm{n}}\left(\mathrm{H}_{3} \mathrm{BTB}=1,3,5\right.$-benzenetribenzoate) [87]. The recyclable performance of this EuMOF was investigated by fast and simple methods. Generally, this EuMOF was immersed in an $\mathrm{PO}_{4}{ }^{3-}$ aqueous solution $\left(10^{-3} \mathrm{M}\right)$ for $20 \mathrm{~s}$ to completely form EuMOF-PO ${ }_{4}{ }^{3-}$, then EuMOF-PO ${ }_{4}{ }^{3-}$ was washed in water several times to obtain the original EuMOF. The results demonstrate the promising practical applications of this recyclable $\mathrm{PO}_{4}{ }^{3-}$ probe.

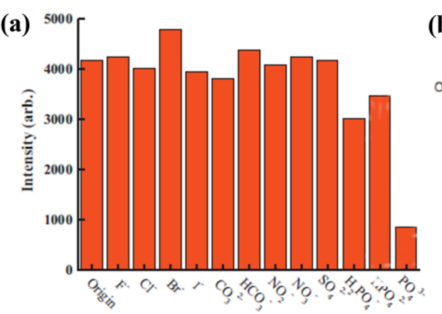

(c)

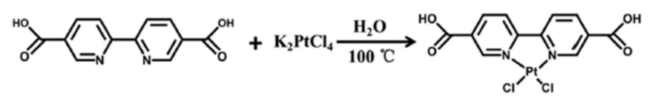

(d)

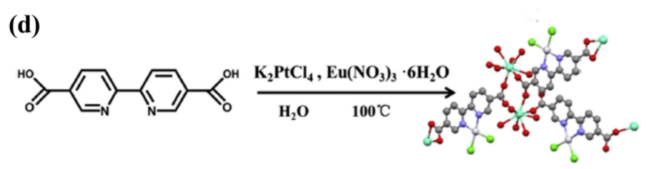

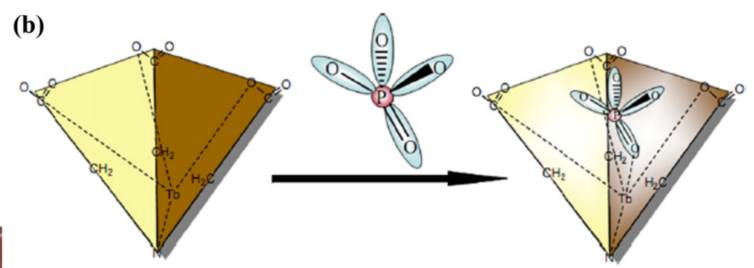

(e)

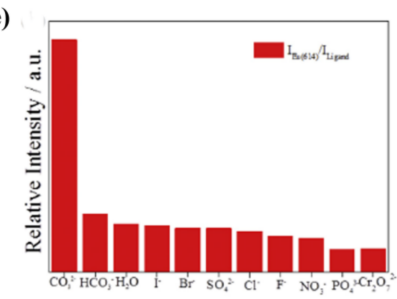

Figure 5. (a) Comparison of the ${ }^{5} \mathrm{D}_{4} \rightarrow{ }^{7} \mathrm{~F}_{5}$ transition intensities of TbNTA solid activated in $10^{-2} \mathrm{M}$ $\mathrm{NaX}$ aqueous solution. (b) A schematic representation of the phosphate anion sensor. Reprinted with permission from [86]. Copyright 2010 Elsevier B.V. (c,d) Schematic illustration of the synthetic process of Eu/Pt-MOFs. The Eu, C, O, Pt, N, and $\mathrm{Cl}$ atoms are represented by blue, grey, red, white, purple and green, respectively. Hydrogen atoms and uncoordinated water molecules are excluded for clarity. (For interpretation of the references to color in this figure legend, the reader is referred to the web version of this article.) (e) A histogram demonstrating the value of $I_{\mathrm{Eu}(614)} / I_{\text {Ligand }}$ according to the fluorescence spectrum. Reprinted with permission from [25]. Copyright 2017 Elsevier Ltd., Toronto, Canada.

Recently, Yan and coworkers reported a heterobimetallic Eu/Pt-MOF with dual emissions from both organic linkers and $\mathrm{Eu}^{3+}$ that exhibited facile, fast, and ratiometric detection of $\mathrm{CO}_{3}{ }^{2-}$ (Figure $5 \mathrm{c}, \mathrm{d}$ ) [25]. The authors posited that the interaction with $\mathrm{CO}_{3}{ }^{2-}$ suppressed the ligand-centered luminescence and enhanced the luminescence of $\mathrm{Eu}^{3+}$, resulting in the maximum intensities ratio of $\mathrm{Eu}^{3+}(614 \mathrm{~nm})$ to ligand (Figure 5e). The results indicate that the ratiometric sensing methodology could be an efficient platform for analytical monitoring of trace $\mathrm{CO}_{3}{ }^{2-}$ in real samples due to the excellent orientation selectivity of $\mathrm{CO}_{3}{ }^{2-}$.

\subsection{LnMOFs for Small Molecule Sensing}

Formaldehyde (HCHO) is widespread in construction, furniture, and particle board, posing an impact on human health, such as watery eyes, asthma, and respiratory irritation [88]. Yu and 
coworkers developed a ratiometric luminescence $\mathrm{HCHO}$ probe through incorporation of $\mathrm{Eu}^{3+}$ ions into $\mathrm{NH}_{2}-\mathrm{UiO}-66$ under microwave irradiation conditions [89]. The dual-emitting luminescence originated from the characteristic red emission of $\mathrm{Eu}^{3+}$ ions $(615 \mathrm{~nm}$ ) and linker-to-cluster (Eu-oxo or Zr-oxo) charge transfer transition-related emission $(465 \mathrm{~nm})$. The interaction of the free amino groups with $\mathrm{HCHO}$ can drastically enhance emission around $465 \mathrm{~nm}$ due to the added electron transfer from the amino group with lone pair electrons to the positively charged $\mathrm{HCHO}$. This is in contrast to the emission of $\mathrm{Eu}^{3+}$ at $615 \mathrm{~nm}$ that was only slightly enhanced. Then, a ratiometric luminescence HCHO probe was performed based on the intensity ratio of two emission bands at $465 \mathrm{~nm}$ and $615 \mathrm{~nm}$. The results indicated that the fabrication of a ratiometric luminescence probe based on multiband luminescent MOFs can serve as a common sensing method for organic molecules. Another ratiometric luminescence sensor for HCHO was reported by Yang and coworkers [90]. This self-calibrating luminescent film was fabricated directly by growing Eu-NDC $\left(\mathrm{H}_{2} \mathrm{NDC}=2,6\right.$-naphthalenedicarboxylate $)$ on hydrolyzed polyacrylonitrile (HPAN) via a layer-by-layer strategy (Figure 6a). The Eu-NDC@HPAN thin film can detect $\mathrm{HCHO}$ via a ratiometric luminescence approach with a 3.2-fold increase of the relative ratio of luminescence intensities at $453 \mathrm{~nm}$ and616 $\mathrm{nm}$. It has been proposed that the Eu-NDC frameworks will decompose after adding $\mathrm{HCHO}$, while the NDC ligands regenerate, resulting in luminescence quenching and enhancing of $\mathrm{Eu}^{3+}$ ions and NDC, respectively (Figure 6b). The remarkable selectivity, sensitivity, and water stability of this film $\mathrm{HCHO}$ probe indicates its potential use in life sciences.

(a)

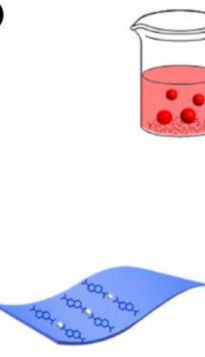

(c)

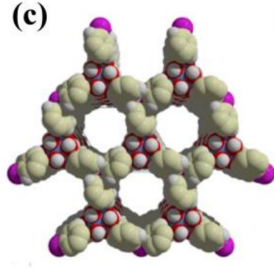

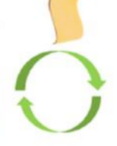
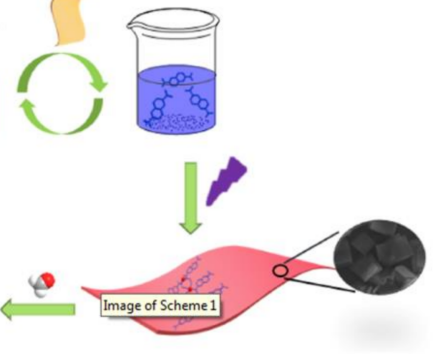

(b)

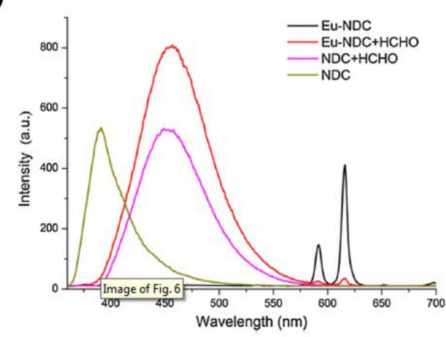

(d)

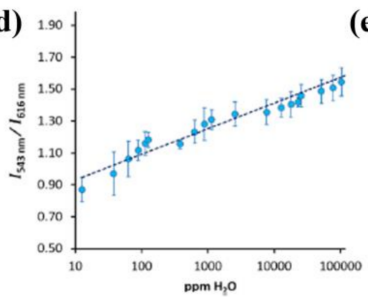

(e)

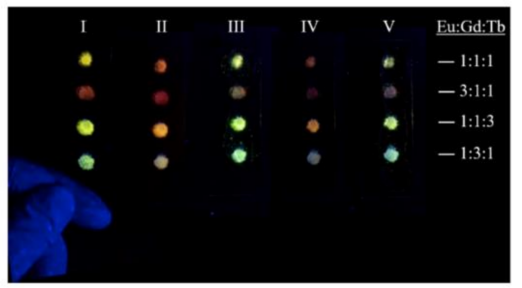

Figure 6. (a) Schematic representation of the synthesis process of Eu-NDC@HPAN and the luminescence quenching phenomenon of formaldehyde (HCHO) to Eu-NDC@HPAN; (b) Luminescence spectra of deprotonated NDC and Eu-NDC $(0.25 \mathrm{mg} / \mathrm{mL}$ ) (before and after treatment with formaldehyde) $\left(\lambda_{\mathrm{ex}}=360 \mathrm{~nm}\right)$. Reprinted with permission from [90]. Copyright 2017 Elsevier B.V.; (c) Space-filling view along the c axis shows 1D hexagonal channels of PCM-22; (d) Relative photoemission response ratios obtained upon the addition of trace $\mathrm{H}_{2} \mathrm{O}$ to $\mathrm{Eu}_{1}$ : $\mathrm{Tb}_{5}-\mathrm{PCM}-22$ presoaked in $\mathrm{D}_{2} \mathrm{O}$ show a linear response. Error bars were obtained from three separate experiments; (e) Model dipstick detectors demonstrated for $\mathrm{H}_{2} \mathrm{O}$ sensing: (I) as-synthesized, (II) desolvated in air with a heat gun, (III) after exposure to $\mathrm{H}_{2} \mathrm{O}$, (IV) reactivation using a heat gun, and (V) re-exposure to $\mathrm{H}_{2} \mathrm{O}$. Reprinted with permission from [91]. Copyright 2017 Elsevier Inc.

Recently, Humphrey and coworkers reported a rare example of a LnMOF probe for detecting trace $\mathrm{H}_{2} \mathrm{O}$ in $\mathrm{D}_{2} \mathrm{O}$ [91]. $\mathrm{D}_{2} \mathrm{O}$ is an isotopically labeled version of $\mathrm{H}_{2} \mathrm{O}$ and is widely used in chemical analysis and medicine [92]. High-purity $\mathrm{D}_{2} \mathrm{O}$ is essential in various spectroscopic and synthetic applications. The codoped PCM-22 $\left[\mathrm{Ln}(\mathrm{tctp})\left(\mathrm{OH}_{2}\right)_{3}\right] \cdot 3(1,4$-dioxane $)\left(\mathrm{Ln}=\mathrm{Eu}^{3+}, \mathrm{Tb}^{3+}\right.$ and $\mathrm{Gd}^{3+}, \mathrm{tctpH}_{3}$ $=$ tris $\left(\mathrm{p}\right.$-carboxylato)triphenylphosphine $\left.\left(\mathrm{P}\left(\mathrm{C}_{6} \mathrm{H}_{4}-p-\mathrm{CO}_{2} \mathrm{H}\right)_{3}\right)\right)$ has a 3D structure consisting of puckered 
2D honeycomb sheets with large hexagonal channels and exhibits the characteristic luminescence of $\mathrm{Eu}^{3+}$ and $\mathrm{Tb}^{3+}$ (Figure 6c). This material allows for immediate solvent identification through color changes, which can easily be observed by the naked eye. Interestingly, the sensor can also be employed to quantitatively detect trace $\mathrm{H}_{2} \mathrm{O}$ in $\mathrm{D}_{2} \mathrm{O}$ (Figure $6 \mathrm{~d}, \mathrm{e}$ ), as well as acetone, ethanol, and acetonitrile by uncomplicated spectrophotometry. To the best of our knowledge, this codoped LnMOF is the first material-based sensor for detecting $\mathrm{H}_{2} \mathrm{O}$ in $\mathrm{D}_{2} \mathrm{O}$ from 10 to 120,000 ppm. Buschbaum et al. proposed a new approach to obtain a ratiometric $\mathrm{H}_{2} \mathrm{O}$ probe by using superparamagnetic microparticles $\mathrm{Fe}_{3} \mathrm{O}_{4} / \mathrm{SiO}_{2}$ as a core and different LnMOFs as a shell [93]. [Eu $\left.\mathrm{Eu}_{2}(\mathrm{BDC})_{3}\right] \cdot 2 \mathrm{H}_{2} \mathrm{O} \cdot 2 \mathrm{DMF}\left(\mathrm{BDC}^{2-}=\right.$ benzene dicarboxylate) and $\left[\mathrm{Ln}_{2} \mathrm{Cl}_{6}(\text { bipy })_{3}\right] \cdot 2$ bipy $(\mathrm{Ln}=\mathrm{Eu}$ and $\mathrm{Tb}$; bipy = 4,4'-bipyridine) were chosen to functionalize the $\mathrm{Fe}_{3} \mathrm{O}_{4} / \mathrm{SiO}_{2}$ core, forming a color-tuned yellow-emitting $\mathrm{Fe}_{3} \mathrm{O}_{4} / \mathrm{SiO}_{2} @$ mixed-MOF composite system. The luminescence of two MOFs decreased unequally upon the presence of $\mathrm{H}_{2} \mathrm{O}$, allowing for a quantitative detection of $\mathrm{H}_{2} \mathrm{O}$ content by the $\mathrm{Tb}^{3+}$ - and $\mathrm{Eu}^{3+}$-based luminescence intensity ratio. In addition, the $\mathrm{Fe}_{3} \mathrm{O}_{4} / \mathrm{SiO}_{2} @$ mixed-MOF composite system can easily be removed from the liquid phase by means of a magnet.

A EuMOF [Eu(FBPT) $\left.\left(\mathrm{H}_{2} \mathrm{O}\right)(\mathrm{DMF})\right]\left(\mathrm{FBPT}=2^{\prime}\right.$-fluoro-biphenyl-3,4',5-tricarboxylate) for sensing acetone was reported by Zhang and coworkers [22]. The luminescence intensity of this EuMOF primarily depends on the organic solvents, particularly in the case of acetone, which exhibited the most significant quenching effect. It has been suggested that the competition of absorbing excited light energy between FBPT and acetone plays an important role in their luminescence diminishment. Guo et al. examined the capability of NIR luminescent $\mathrm{YbMOF} \mathrm{Yb}(\mathrm{BPT})\left(\mathrm{H}_{2} \mathrm{O}\right) \cdot(\mathrm{DMF})_{1.5}\left(\mathrm{H}_{2} \mathrm{O}\right)_{1.25}$ (BPT = biphenyl-3,4',5-tricarboxylate) for organic molecule sensing (Figure 7a-c) [94]. When excited at $326 \mathrm{~nm}$, the active $\mathrm{Yb}(\mathrm{BPT})$ exhibits typical NIR emission of $\mathrm{Yb}^{3+}$ ions at $980 \mathrm{~nm}$ (Figure 7d). The NIR emission showed significant quenching and enhancement effects in the presence of acetone and DMF, respectively (Figure 7e). This study opens up a new approach for luminescent MOF-based sensors with NIR emission, demonstrating their potential applications in biological systems. Liu and coworkers synthesized a heterometallic MOF, $\left\{\left[\mathrm{Tb}_{2}(\mathrm{ODA})_{6} \mathrm{Cd}_{3}\left(\mathrm{H}_{2} \mathrm{O}\right)_{6}\right] \cdot 6 \mathrm{H}_{2} \mathrm{O}\right\}_{n}(\mathrm{ODA}=$ oxydiacetic acid), that can selectively detect ethanol and 2-propanol with luminescence turn-on and turn-off responses, respectively [95]. A series of MOFs composed of 4,4'-oxybis(benzoate) (OBA) ligands and suitable cations were reported by Hus and coworkers [96]. The MOF $\mathrm{Na}\left[\mathrm{Tb}(\mathrm{OBA})_{2}\right]_{3} \cdot 0.4 \mathrm{DMF}_{3} \cdot 1.5 \mathrm{H}_{2} \mathrm{O}$ shows the strongest emission in the presence of $\mathrm{BuOH}$ and $\mathrm{EtOH}$, whereas a much weaker emission was found in the presence of $\mathrm{MeOH}$ and $\mathrm{H}_{2} \mathrm{O}$. One possible mechanism explaining this is that $\mathrm{MeOH}$ and $\mathrm{H}_{2} \mathrm{O}$ are trapped in the MOF cavities entering the coordination spheres of $\mathrm{Tb}^{3+}$. This potentially causes the luminescence quenching effect. The $\mathrm{EtOH}$ and $\mathrm{BuOH}$ molecules then protect the $\mathrm{Tb}^{3+}$ from quenching by $\mathrm{O}-\mathrm{H}$ oscillators because of the relatively sterical bulky alkyl groups. Wang et al. reported a codoped LnMOF, $\left[\mathrm{LnL}_{5}\left(\mathrm{H}_{2} \mathrm{O}\right)_{2}\right] \cdot 2 \mathrm{H}_{2} \mathrm{O}\left(\mathrm{Ln}=\mathrm{Eu}\right.$ and $\mathrm{Tb}, \mathrm{H}_{3} \mathrm{~L}_{5}=4$-(2-carboxyphenoxy)benzene-1,3-dioic acid) showing good sensitivity to $\mathrm{CH}_{3} \mathrm{CN}$ and nitrobenzene [97]. The emission can be enhanced remarkably in the presence of $\mathrm{CH}_{3} \mathrm{CN}$, while nitrobenzene can significantly quench the emission. 

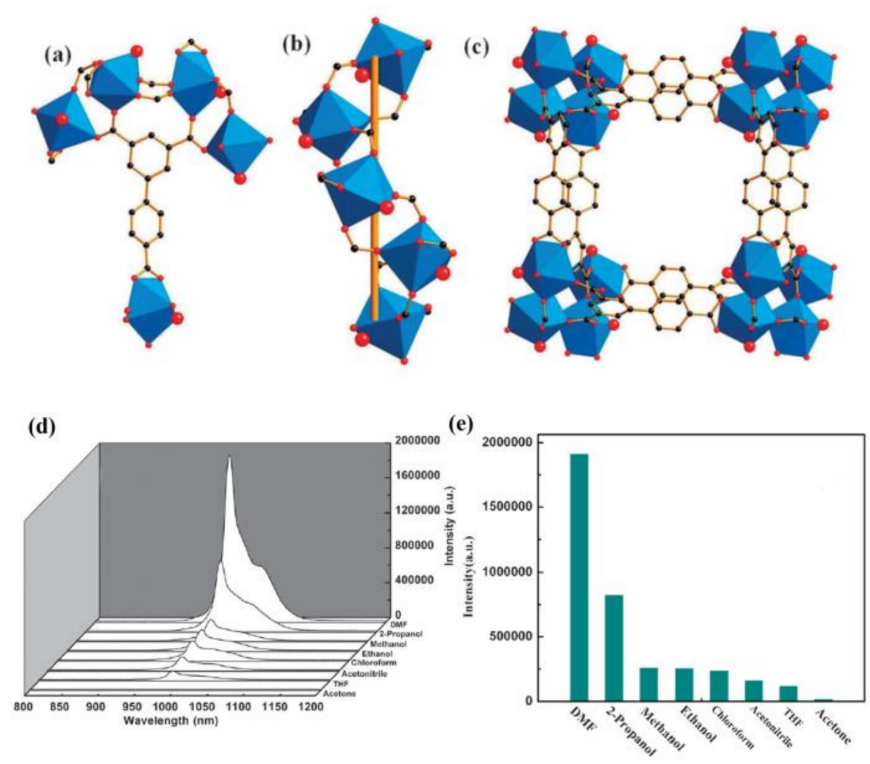

Figure 7. Crystal structure of YbMOF indicating (a) the BPT tricarboxylate linker and coordination environments of all $\mathrm{Yb}$ atoms related by symmetry; $(\mathbf{b}) 1 \mathrm{D}$ helical $\operatorname{rod}\left[\mathrm{Yb}\left(\mathrm{CO}_{2}\right)_{3}\right]_{n}$ as the infinite SBU; and (c) 1D micropore of about 7.2 × 7.2 $\AA$ along c axis (Yb, blue polyhedra; C, black; O, red: terminal water molecules, large red sphere); (d) the PL spectra; and (e) the ${ }^{2} \mathrm{~F}_{5 / 2}-{ }^{2} \mathrm{~F}_{7 / 2}$ transition intensities of YbMOF introduced into various pure solvent emulsions when excited at $304 \mathrm{~nm}$. Reprinted with permission from [94]. Copyright 2011 The Royal Society of Chemistry.

Benzene and its homologues, a prime type of toxic pollutant, bring great harm to both the environment and humans. It is therefore of significant importance to develop an efficient and easily processed approach to detect this kind of pollutant. Cheng and coworkers constructed a red luminescence sensor based on $\left\{\left[\mathrm{Eu}_{2}\left(\mathrm{~L}_{6}\right)_{3}(\mathrm{DMF})_{2}\right] \cdot \mathrm{DMF} \cdot \mathrm{MeOH}\right\}_{n}\left(\mathrm{H}_{2} \mathrm{~L}_{6}=5-(4 \mathrm{H}-1,2,4\right.$-triazol-4-yl) benzene-1,3-dicarboxylic acid) to effectively detect polychlorinated benzenes [98]. This EuMOF represents a highly efficient quenching effect on detecting polychloriznated benzenes, including 1,2,4-trichlorobenzene, 1,2,3,4-tetrachlorobenzene, 1,2,4,5-tetrachlorobenzene, pentachlorobenzene, and hexachlorobenzene, which can be ascribed to the competition of the absorption of the excitation light between the analytes and ligands. Weng et al. fabricated a dual-emissive hybrid $\mathrm{N}-G Q D s / \mathrm{Eu}^{3+} @ \mathrm{Mg}-\mathrm{MOF}\left(\mathrm{N}-\mathrm{GQDs}=\mathrm{N}\right.$ atom-doped graphene quantum dot, $\mathrm{Mg}-\mathrm{MOF}=\left\{\left[\mathrm{Mg}_{3}(\mathrm{ndc})_{2.5}\right.\right.$ $\left.\left.\left(\mathrm{HCO}_{2}\right)_{2}\left(\mathrm{H}_{2} \mathrm{O}\right)\right]\left[\mathrm{NH}_{2} \mathrm{Me}_{2}\right] \cdot 2 \mathrm{H}_{2} \mathrm{O} \cdot \mathrm{DMF}\right\}$ 1,4-ndc $=1$,4-naphthalenedicarboxylate $)$ and employed it as a ratiometric luminescence sensor for decoding benzene homologues [53]. It exhibits dual-emission of $\mathrm{N}-G Q D s$ and $\mathrm{Eu}^{3+}$ when excited at $394 \mathrm{~nm}$, while the emission of the ligands and $\mathrm{Eu}^{3+}$ can be collected when excited at $349 \mathrm{~nm}$. Thus, a $2 \mathrm{D}$ decoded map with $I_{\mathrm{L}} / I_{\mathrm{Eu}}$ as abscissa and $I_{\mathrm{Eu}} / I_{\mathrm{N}-\mathrm{GQDs}}$ as ordinate is established to identify benzene homologues. The results demonstrated that the decoded map can be used for the precise recognition of unknown compounds.

\subsection{LnMOFs for Nitroaromatic Explosive Sensing}

It is of great importance to selectively and rapidly detect nitroaromatic explosives in environmental monitoring, civilian safety, and homeland security [99]. The current methods for explosive detection are limited by their equipment demands and cost drawbacks [100]. However, luminescence sensing has proven to be an excellent detection technique for explosives owing to its speed and cost effectiveness, as well as to the fact that it is easily portable [101].

The detection of explosives using LnMOF-based luminescence sensors is usually performed in a turn-off manner. The luminescence quenching effect can be assigned to the photoinduced electron or energy transfer. The conduction band (CB) of the electron-rich MOF lies higher than the lowest 
unoccupied molecular orbitals (LUMOs) energy of the electron-deficient analytes. This allows for the electron transfer from the CB of the MOF sensors to the LUMOs of nitro analytes causing luminescence quenching [102]. Another possible mechanism for luminescence quenching is the competition of the absorption of the excitation light energy between the MOF ligands and nitro analytes. Based on these two possible sensing mechanisms, great success has been reported for sensing nitroaromatic explosives, such as nitrobenzene (NB), m-nitrotoluene (m-NT), o-nitrotoluene (o-NT), 3-nitrophenol (3-NP), 4-nitrophenol (4-NP), 2,4-dinitrophenol (2,4-NP), 2,4,6-trinitrophenol (TNP), and 2,4,6-trinitrotoluene (TNT) (Figure 8) [103-107].

The luminescence quenching efficiency of LnMOFs towards nitroaromatic explosives was analyzed using a quenching constant $K_{s v}\left(\mathrm{M}^{-1}\right)$ and detection limits. The quenching constant $K_{s v}$ $\left(\mathrm{M}^{-1}\right)$ is calculated by using the Stern-Volmer (SV) equation, $\left(I_{0} / I\right)=K_{\mathrm{sv}}[\mathrm{A}]+1$, where $I_{0}$ and $I$ are the luminescence intensities before and after the addition of the analyte, respectively, and where [A] is the molar concentration of the analyte. The detection limit was calculated by $K_{\mathrm{sv}}$ values and the standard deviation $\left(S_{\mathrm{b}}\right)$, defined as $\mathrm{n} S_{\mathrm{b}} / K_{\mathrm{sv}}[108]$.
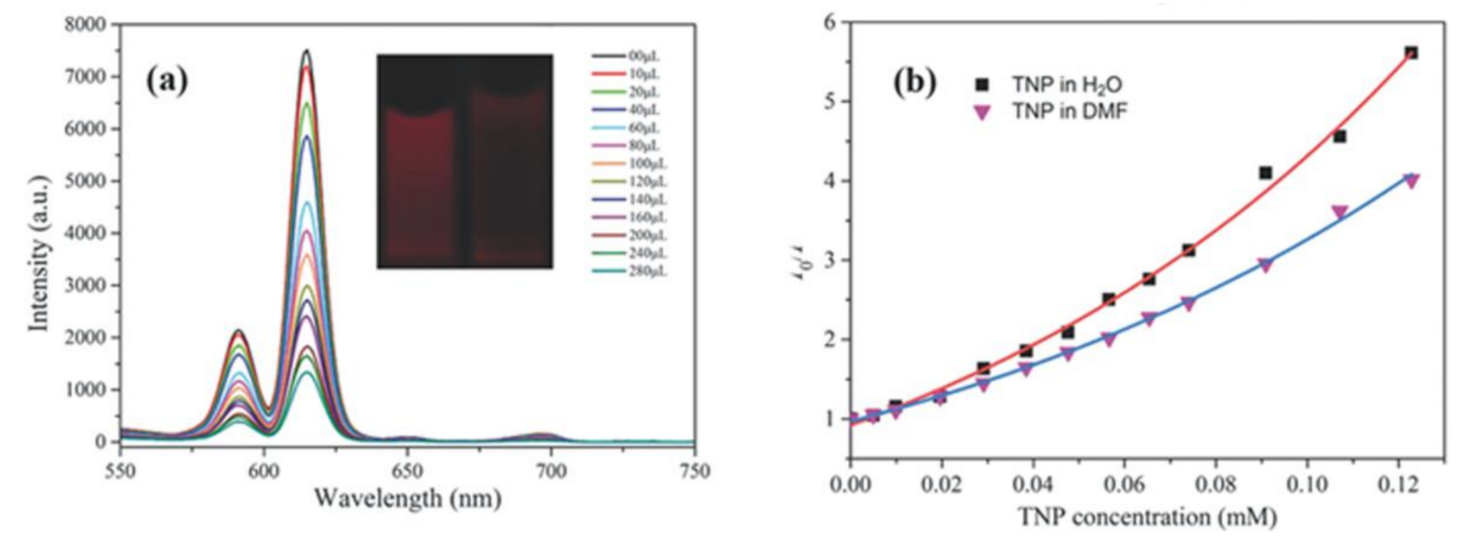

Figure 8. (a) Effect on the emission spectra of the activated EuMOF dispersed in $\mathrm{H}_{2} \mathrm{O}$ upon incremental addition of a 2,4,6-trinitrophenol (TNP) aqueous solution $(1 \mathrm{mM})\left(\lambda_{\mathrm{ex}}=362 \mathrm{~nm}\right)$. The legend indicates the overall concentration of TNP. Inset: A photograph showing the original fluorescence (left) and the fluorescence quenching (right) upon the addition of $280 \mu \mathrm{L}$ TNP (UV light, $365 \mathrm{~nm}$ ). (b) Stern-Volmer plots of $I_{0} / I$ versus the TNP concentration in DMF and water. Reproduced with permission from [107]. Copyright 2014 Wiley-VCH.

\subsection{LnMOFs for Gas and Vapor Sensing}

The luminescent MOF films, CPM-5つ $\bigcap \mathrm{Tb}^{3+}$ and MIL-100(In) $\supset \bigcap \mathrm{Tb}^{3+}$, were designed by Qian and coworkers as a fast-response oxygen probe (Figure 9a,b) [109]. The luminescence intensities of the activated CPM-5 $\supset \mathrm{Tb}^{3+}$ and MIL-100(In) $\supset \bigcap \mathrm{Tb}^{3+}$ decreased gradually with increasing $\mathrm{O}_{2}$ pressure.

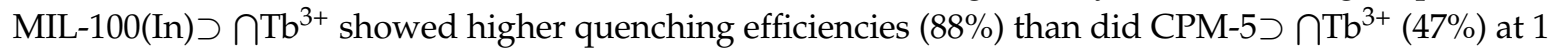
atm of $\mathrm{O}_{2}$ (Figure 9c,d). This is because the exposed carboxylate acids in MIL-100(In) can form Tb-O bonds with $\mathrm{Tb}^{3+}$ ions, leading to the intramolecular energy transfer, whilst $\mathrm{Tb}^{3+}$ merely balances cations in the pores of CPM-5, leading to intermolecular energy transfer. The high-oxygen sensitivity and short response/recovery time of MIL-100(In) $\supset \bigcap \mathrm{Tb}^{3+}$ indicate their potential in sensing gases or vapors. 

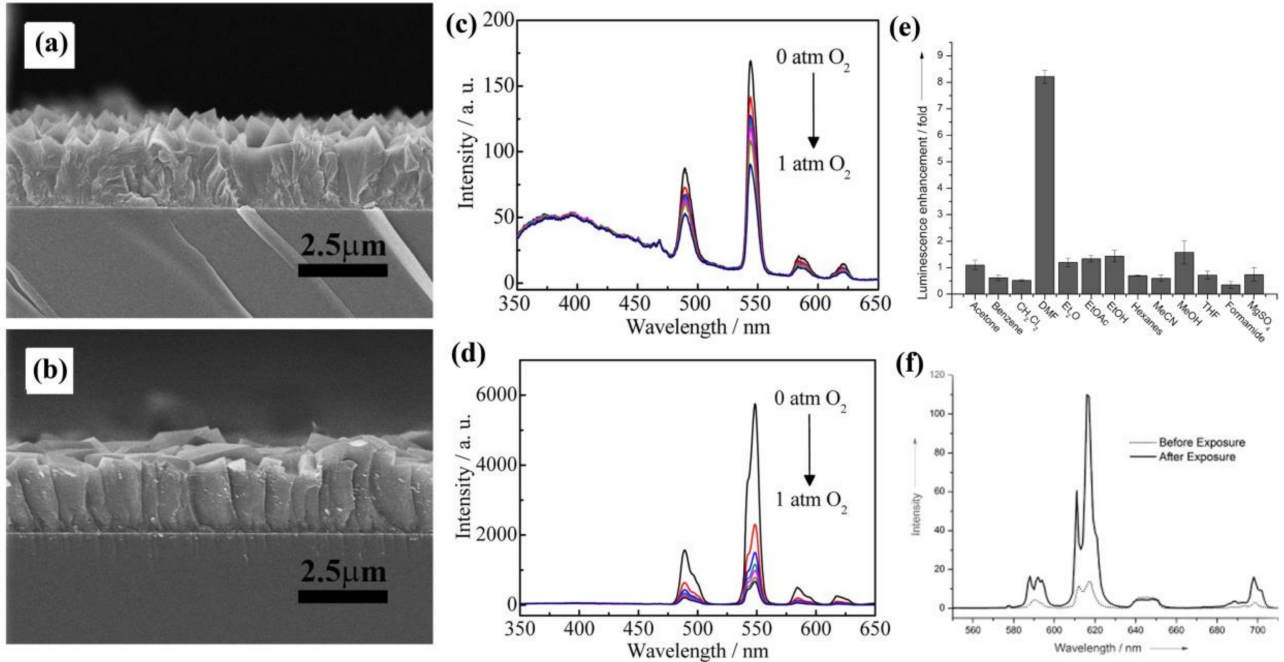

Figure 9. SEM images of CPM-5つ $\bigcap \mathrm{Tb}^{3+}$ (a) and MIL-100(In) $\supset \bigcap \mathrm{Tb}^{3+}$ (b) films. Emission spectra of activated (c) CPM-5 $\supset \mathrm{Tb}^{3+}$ and (d) MIL-100(In) $\supset \bigcap \mathrm{Tb}^{3+}$ films under different oxygen partial pressure $\left(\mathrm{Po}_{2}\right)$. Reproduced with permission from [109]. Copyright 2014 American Chemical Society. (e) Increase in Eu emission intensity of $\left[\mathrm{Eu}_{2} \mathrm{~L}_{3}\left(\mathrm{H}_{2} \mathrm{O}\right)_{4}\right] \cdot 3 \mathrm{DMF}\left(I_{\text {after }} / I_{\text {before }}-1\right)$ after incubation for 24 $\mathrm{h}$ under various solvent vapors and with anhydrous $\mathrm{MgSO}_{4}$. The intensity is measured at $616 \mathrm{~nm}$. Error bars indicate the standard deviations of three or four parallel experiments. (f) Emission spectra of $\left[\mathrm{Eu}_{2} \mathrm{~L}_{3}\left(\mathrm{H}_{2} \mathrm{O}\right)_{4}\right] \cdot 3 \mathrm{DMF}$ before and after exposure to DMF vapor (excitation at $323 \mathrm{~nm}$ ). The broad peak around $640 \mathrm{~nm}$ arises from scattering. Reproduced with permission from [110]. Copyright 2013 Wiley-VCH, Weinheim, Germany.

Song and coworkers exploited a EuMOF $\left[\mathrm{Eu}_{2}\left(\mathrm{~L}_{7}\right]_{3}\left(\mathrm{H}_{2} \mathrm{O}\right)_{4}\right] \cdot 3 \mathrm{DMF}\left(\mathrm{L}_{7}=2^{\prime}, 5^{\prime}\right.$-bis(methoxymethyl)$\left[1,1^{\prime}: 4^{\prime}, 1^{\prime \prime}\right.$-terphenyl]-4,4"-dicarboxylate) for sensing DMF vapor with a turn-on response [110]. A water-exchanged framework was formed by submerging the EuMOF in distilled water for 3 days and consequently showed much weaker $\mathrm{Eu}^{3+}$-based emission due to the quenching effect of the water molecules. The $\mathrm{Eu}^{3+}$ luminescence intensity exhibits a more than eightfold increase in the presence of DMF vapor. This is primarily due to partial replacement of the channel water by DMF molecules that reduce the quenching effect of the water molecules. This explanation was further confirmed by the fluorescence decay of deuteroxide- and water-exchanged samples. Moreover, DMF molecules within the channels of the compound can also modulate the energy levels of the ligands, thus promoting the LMCT process, all confirmed by NMR and XRD studies.

Besides the distinct rotten egg smell for which this toxic gas is commonly known, hydrogen sulfide $\left(\mathrm{H}_{2} \mathrm{~S}\right)$ is of great importance in biological systems, as well as the cause of acid rain and other environmental problems [111]. Tan and coauthors developed a ratiometric sensor for $\mathrm{H}_{2} \mathrm{~S}$ based on $\mathrm{Cu}^{2+}{ }_{-}$-mediated fluorescence of LnCPs doped with carbon dots (CDs) (CDs@ZIF-8@GMP/Tb) [112]. GMP/Tb on the surface of ZIF-8 (zeolitic imidazolate framework-8) displays a typical ON-OFF-ON behavior upon the sequential addition of $\mathrm{Cu}^{2+}$ and $\mathrm{H}_{2} \mathrm{~S}$, an observation that can be put to use in response signaling (Figure 10a,b). The fluorescence of the CDs of CDs@ZIF-8@GMP/Tb remains unchanged in the presence of $\mathrm{Cu}^{2+}$ or/and $\mathrm{H}_{2} \mathrm{~S}$, empowering $\mathrm{CDs}$ to be of good reference. As a result, a ratiometric fluorescence sensor based on CDs@ZIF-8@GMP/Tb for sensing $\mathrm{H}_{2} \mathrm{~S}$ was fabricated (Figure 10c). The high selectivity towards $\mathrm{H}_{2} \mathrm{~S}$ against other anions (e.g., thiols and biological species) and the distinct feature of reversible sensing of this ratiometric sensor will promote the development of more sensitive ratiometric sensors based on LnMOFs. Another $\mathrm{H}_{2} \mathrm{~S}$ probe was reported by Yang and coworkers based on the postsynthetic modification of $\mathrm{Tb}^{3+} @ \mathrm{Cu}-\mathrm{MOF}$ [113]. The Tb ${ }^{3+} @ \mathrm{Cu}-\mathrm{MOF}$ (Cu-MOF: $\left[\mathrm{Cu}(\mathrm{HCPOC})_{2}\right]_{n} \mathrm{H}_{2} \mathrm{CPOC}=5$-( $4^{\prime}$-carboxylphenoxy) nicotinic acid $)$ exhibits a typically weak

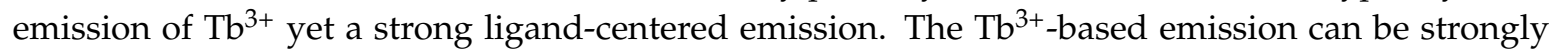


enhanced by $\mathrm{H}_{2} \mathrm{~S}$ due to its superior affinity towards $\mathrm{Cu}^{2+}$ ions. The detection performance of $\mathrm{Tb}^{3+} @ \mathrm{Cu}-\mathrm{MOF}(1.20 \mu \mathrm{M})$ is capable of meeting that of biological systems indicating its potential in real-time organismal $\mathrm{H}_{2} \mathrm{~S}$ sensing.

(a)

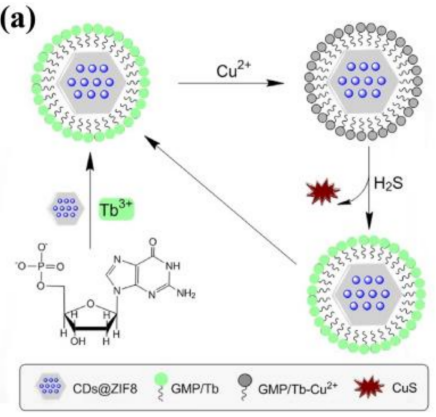

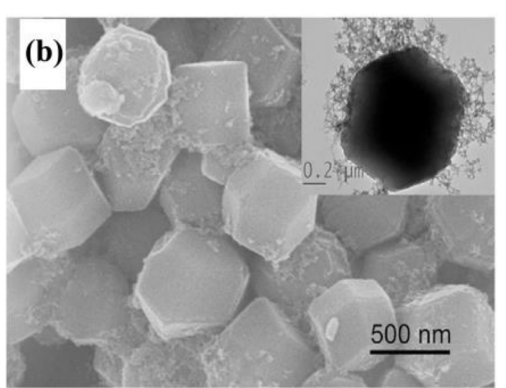

(c)

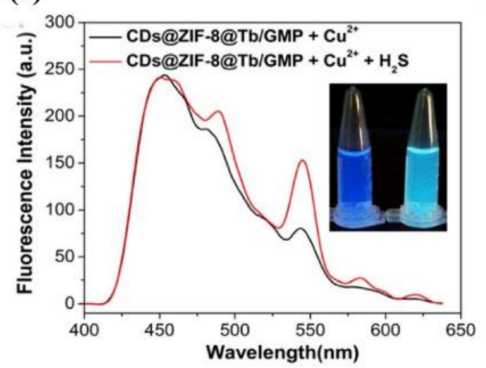

Figure 10. (a) Schematic illustration of the preparation of CDs@ZIF-8@GMP/Tb and its working principle for ratiometric detection of $\mathrm{H}_{2} \mathrm{~S}$; (b) SEM images of CDs@ZIF-8@GMP/Tb. Inset is the corresponding TEM image; (c) Emission spectra of CDs@ZIF-8@Tb/GMP in the presence of $\mathrm{Cu}^{2+}$ and $\mathrm{Cu}^{2+}+\mathrm{H}_{2} \mathrm{~S}$. Reproduced with permission from [112]. Copyright 2017 Elsevier B.V., New York, NY, USA.

Tanase and coworkers reported a dual-mode humidity sensor based on a EuMOF $\left[\mathrm{Eu}\left(\mathrm{H}_{2} \mathrm{O}\right)_{2}(\mathrm{mpca})_{2} \mathrm{Eu}\left(\mathrm{H}_{2} \mathrm{O}\right)_{6} \mathrm{~W}(\mathrm{CN})_{8}\right] \cdot n \mathrm{H}_{2} \mathrm{O}$ (mpca = 2-pyrazine-5-methyl-carboxylate) [114]. This EuMOF has a robust three-dimensional network with significant hydrophilic open channels filled with water molecules. The luminescence intensity of the EuMOF gradually decreases as the humidity increases. This effective and remarkably reliable humidity sensor also shows good linearity over a broad humidity range from $0 \%$ to $100 \% \mathrm{RH}$. Moreover, this sensing material was also examined for electrical detection methods. The recovery time of these methods was found to be similar to that in the photoluminescence measurement.

\subsection{LnMOFs for $\mathrm{pH}$ Sensing}

The need to explore fast $\mathrm{pH}$ sensing in industry, biomedicine, and many other environmental fields in order to monitor $\mathrm{pH}$ values and changes in biological systems and living cells has recently become of top priority [115]. The advantages of luminescence-based $\mathrm{pH}$ probes including quick response and high sensitivity, as well as easy operation, making them particularly desirable [116]. Chen and coworkers designed a pH-sensitive MOF nanoparticle using DMF and 1,10-phenanthroline (Phen) as ligands with $\mathrm{Tb}^{3+}$ ions based on the intramolecular-charge-transfer (ICT) effect [117]. A DMF molecule contains both an electron-donor and -acceptor part, allowing it to generate ICT [118]. It can furthermore change the $\mathrm{Tb}^{3+}$-based luminescence through the antenna effect. Consequently, the protonation of $\mathrm{H}^{+}$could change the charge transfer of DMF and further change the antenna effect for $\mathrm{Tb}^{3+}$, in turn resulting in a change of $\mathrm{Tb}^{3+}$-based luminescence. The Phen molecule in the nanoparticle was used to improve such a change and reduce the luminescence quenching effect of $\mathrm{Tb}^{3+}$ by replacing the coordinated water molecules. The emission intensity of DMF-Tb was improved approximately 4 times, while the emission intensity of DMF-Tb-Phen was improved 10 times due to a decrease of the ICT effect and increase of the antenna effect on the $\mathrm{Tb}^{3+}$ ions upon adding $\mathrm{H}^{+}$. This MOF nanoparticle $\mathrm{pH}$ sensor with high specificity and sensitivity could be used in strong acidic conditions, indicating its potential applications in biological systems. Qian and coworkers fabricated a fluorescence $\mathrm{pH}$ sensor by encapsulating $\mathrm{Eu}^{3+}$ ions into the pores of the nanoscale UiO-67-bpydc (bpydc = 2,2'-bipyridine-5,5'-dicarboxylic acid) [119]. The luminescence intensity of Eu ${ }^{3+} @ U i O-67-b p y d c$ shows a significant luminescence turn-off response in acidic solutions while exhibiting florescence enhancement in basic solutions. This is because protonation and deprotonation of the ligands first change the excited-state energy level of the ligands followed by a change in ligand-to-Eu energy transfer efficiency, explaining the different changes in the $\mathrm{Eu}^{3+}$-based luminescence. This $\mathrm{Eu}^{3+} @ \mathrm{UiO}-67-b p y d c$ 
$\mathrm{pH}$ sensor is stable within a wide $\mathrm{pH}$ range of 1.06 to 10.99 and can thus be used in physiological environments $(\mathrm{pH}=6.80-7.60)$. The bio-compatibility of $\mathrm{Eu}^{3+} @ \mathrm{UiO}-67-b p y d c$ was further confirmed by an MTT (MTT = 3-(4,5-dimethylthiazol-2-yl)-2,5-diphenyl-tetrazolium bromide) assay. Cell imaging results demonstrate that the $\mathrm{Eu}^{3+} @ \mathrm{UiO}-67-b p y d c \mathrm{pH}$ probe could be a promising candidate for monitoring $\mathrm{pH}$ both in vitro and in vivo. Very recently, the same group reported another luminescence $\mathrm{pH}$ sensor based on a nanoscale mixed $\mathrm{LnMOF} \mathrm{Eu}_{0.034} \mathrm{~Tb}_{0.966}(\mathrm{fum})_{2}(\mathrm{ox})\left(\mathrm{H}_{2} \mathrm{O}\right)_{4}$ (fum $=$ fumarate, ox = oxalate) [120]. The $\mathrm{Eu}_{0.034} \mathrm{~Tb}_{0.966}(\text { fum })_{2}(\mathrm{ox})\left(\mathrm{H}_{2} \mathrm{O}\right)_{4} \mathrm{pH}$ sensor shows high stability in aqueous solutions. Moreover, its morphology and size can easily be adjusted by changing the amount of CTAB surfactant. The mixed LnMOF exhibits both $\mathrm{Tb}^{3+}(545 \mathrm{~nm})$ and $\mathrm{Eu}^{3+}(618 \mathrm{~nm})$ emissions, which can be used for sensing $\mathrm{pH}$ values ranging from 3.00 to 7.00 in a ratiometric manner (Figure 11a-c). The MTT analysis and optical microscopy assay show that this mixed LnMOF sensor has low cytotoxicity and favorable biocompatibility (Figure 11e-f), indicating its potential to be applied as a $\mathrm{pH}$ sensor in physiological environments.
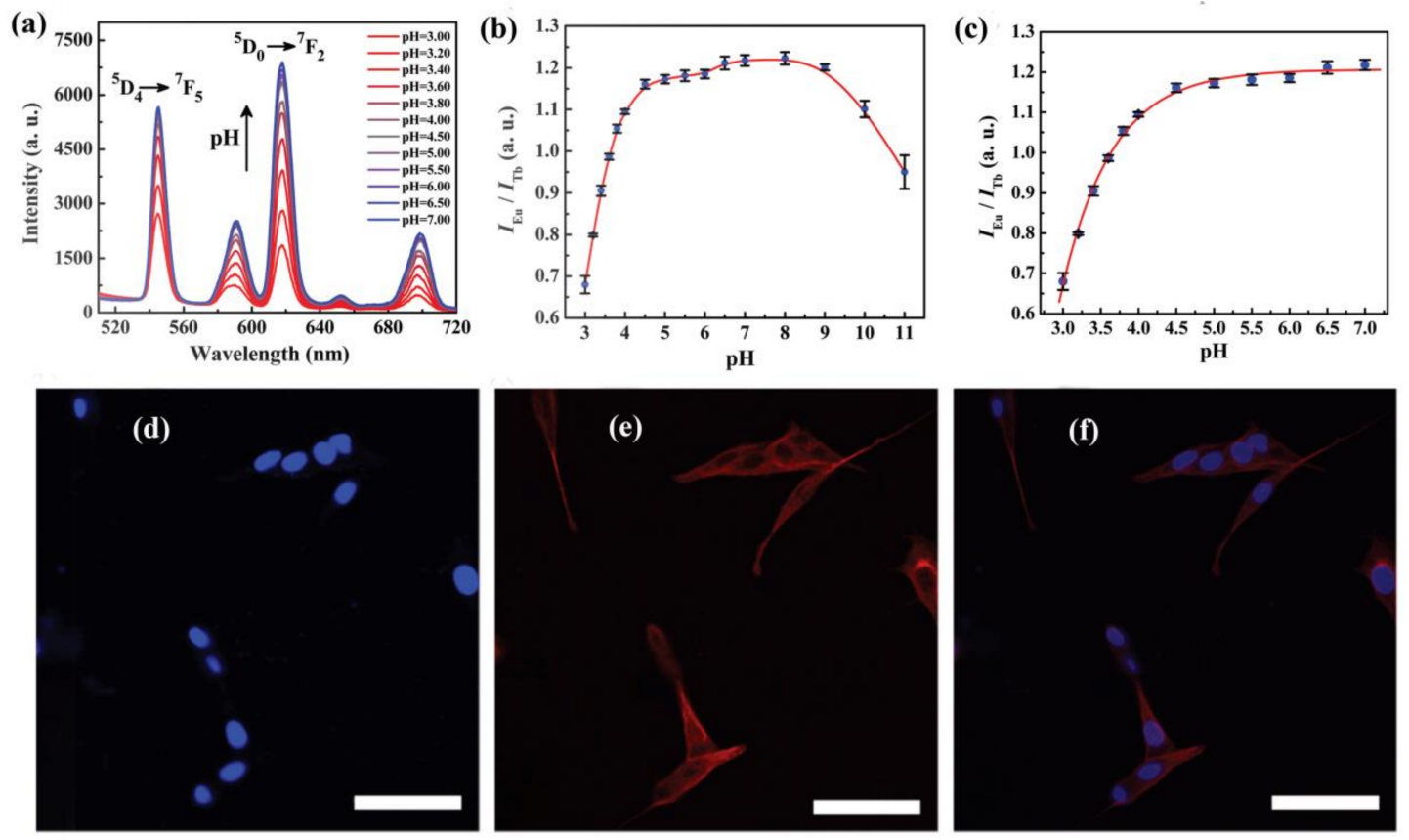

Figure 11. (a) pH-dependent emission spectra of $\mathrm{Eu}_{0.034} \mathrm{~Tb}_{0.966}-\mathrm{NMOF}(\mathrm{W}=20, \mathrm{~W}$ is defined as the water-to-surfactant molar ratio) in the $\mathrm{pH}$ ranging from 3.00 to 7.00; (b) $\mathrm{pH}$-dependent intensity ratio of $\mathrm{Eu}^{3+}(618 \mathrm{~nm})$ to $\mathrm{Tb}^{3+}(545 \mathrm{~nm})$ in the $\mathrm{pH}$ ranging from 3.00 to 11.00; (c) The fitted curve of $\mathrm{Eu}_{0.034} \mathrm{~Tb}_{0.966}$-NMOF $(\mathrm{W}=20)$ in the $\mathrm{pH}$ ranging from 3.00 to $7.00 ;(\mathbf{d}, \mathbf{e})$ fluorescence and (f) overlapped confocal microscopy images of fixed PC12 cells incubated with $50 \mu \mathrm{g} \cdot \mathrm{mL}^{-1} \mathrm{Eu}_{0.034} \mathrm{~Tb}_{0.966}-\mathrm{NMOF}$ for $24 \mathrm{~h}$. Microtubular cytoskeleton (tubulin, red) and nuclei (blue) were fluorescently stained. The scale bar is $50 \mu \mathrm{m}$. Reproduced with permission from [120]. Copyright 2017 The Royal Society of Chemistry.

\subsection{LnMOFs for Temperature Sensing}

Temperature is an important thermodynamic parameter in human life and scientific investigations. Therefore, accurate temperature measurement is essential in both scientific and human development. Among the approaches for temperature determination, luminescence-based measurements have achieved tremendous attention with regards to their prominent advantages, including noninvasiveness, fast response, accuracy, high spatial resolution, and ability to work in strong electro or magnetic fields [121]. However, the most luminescent thermometers depend on a single emission susceptible to errors because of sample concentration changes and drifts of the optoelectronic system. 
Qian and coworkers fabricated the first self-calibrated luminescent temperature sensor using a mixed LnMOF $\mathrm{Eu}_{0.0069} \mathrm{~Tb}_{0.9931}$-DMBDC (DMBDC = 2,5-dimethoxy-1,4-benzenedicarboxylate) [37]. For Tb-DMBDC and Eu-DMBDC, the characteristic luminescence gradually decreases because of thermal activation of nonradiative decay pathways. However, $\mathrm{Eu}_{0.0069} \mathrm{~Tb}_{0.9931}$-DMBDC exhibits a significant temperature-dependent luminescent behavior as the temperature increases from 10 to $300 \mathrm{~K}$. The $\mathrm{Tb}^{3+}$-based emission in $\mathrm{Eu}_{0.0069} \mathrm{~Tb}_{0.9931}$-DMBDC decreases as the temperature increases, while that of the $\mathrm{Eu}^{3+}$ ions increases. This can be ascribed to the efficient energy transfer from $\mathrm{Tb}^{3+}$ to $\mathrm{Eu}^{3+}$ based on the phonon-assisted Förster transfer mechanism, an effect confirmed by luminescence lifetime measurements. The good linear relationship between the $I_{\mathrm{Tb}} / I_{\mathrm{Eu}}$ ratio and temperature in the range of 50-200 K suggests that $\mathrm{Eu}_{0.0069} \mathrm{~Tb}_{0.9931}$-DMBDC is an excellent temperature thermometer within this temperature range. These results suggest that mixed LnMOFs featuring temperature-dependent luminescence can be ideal candidates for self-referencing temperature sensing. Since then, many mixed LnMOFs have been fabricated for temperature measurement based on similar luminescent behavior [122].

In 2015, another mixed LnMOF $\left(\mathrm{Nd}_{0.577} \mathrm{Yb}_{0.423}\right)_{2}\left(\mathrm{BDC}-\mathrm{F}_{4}\right)_{3}(\mathrm{DMF})\left(\mathrm{H}_{2} \mathrm{O}\right) \cdot \mathrm{DMF}\left(\mathrm{H}_{2} \mathrm{BDC}-\mathrm{F}_{4}=\right.$ 2,3,5,6-tetrafluoro-1,4-benzenedicarboxylate) with typical NIR emission for temperature sensing was designed by Qian and coworkers (Figure 12a) [123]. NIR emission can enter the biological system because of its relatively small adsorption and scattering. Thus, such NIR temperature thermometers have great potential for monitoring temperature in biological systems. The intensity ratio of $\mathrm{Nd}^{3+}$ at $1060 \mathrm{~nm}$ and $\mathrm{Yb}^{3+}$ at $980 \mathrm{~nm}$ is linearly related to temperatures in the physiological range (293-313 K) with a relative sensitivity of $0.816 \% \mathrm{~K}^{-1}$ at $313 \mathrm{~K}$ (Figure $12 \mathrm{~b}, \mathrm{c}$ ), suitable for use in biomedical diagnosis.

(a)

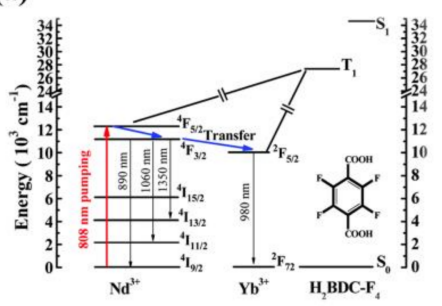

(b)

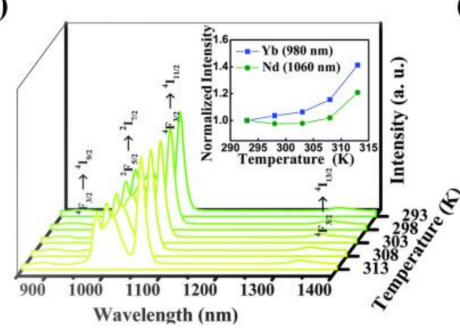

(c)

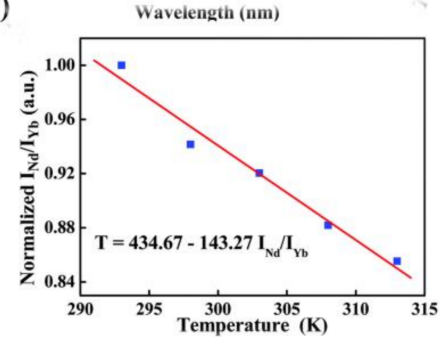

Figure 12. (a) Schematic representation of energy processes in $\mathrm{Nd}_{0.577} \mathrm{Yb}_{0.423} \mathrm{BDC}-\mathrm{F}_{4}$. (b) Emission spectra of $\mathrm{Nd}_{0.577} \mathrm{Yb}_{0.423} \mathrm{BDC}-\mathrm{F}_{4}$ in the range of $293-313 \mathrm{~K}$ excited at $808 \mathrm{~nm}$; inset: temperature dependence of the normalized intensity of the corresponding transitions. (c) Temperature-dependent intensity ratio of $\mathrm{Nd}^{3+}(1060 \mathrm{~nm})$ to $\mathrm{Yb}^{3+}(980 \mathrm{~nm})$ and the fitted curve for $\mathrm{Nd}_{0.577} \mathrm{Yb}_{0.423}$ BDC- $\mathrm{F}_{4}$. Reproduced with permission from [123]. Copyright 2015 The Royal Society of Chemistry.

More recently, Qian and coworkers suggested that ratiometric temperature sensors can be

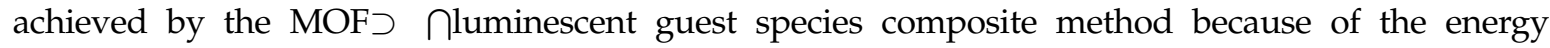

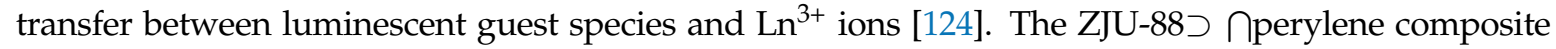

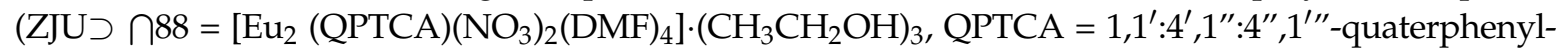
$3,3^{\prime \prime \prime}, 5,5^{\prime \prime \prime}$-tetracarboxylic acid)) was designed as a dual-emitting thermometer with high sensitivity

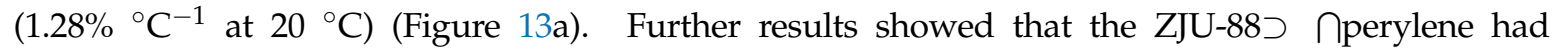
good stability, an outstanding linear relationship, and excellent biocompatibility under simulated physiological conditions (Figure 13b,c), all indicating its potential use as a luminescent thermometer in biological applications. 
(a)

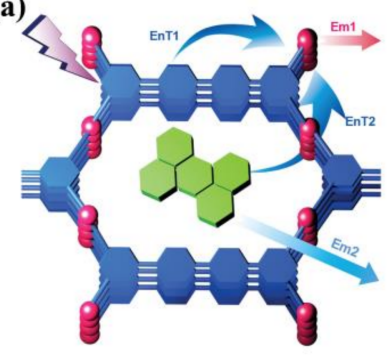

(b)

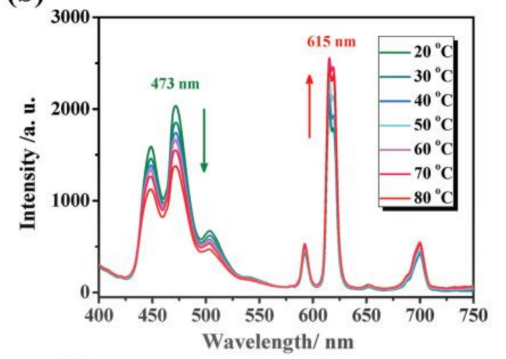

(c)

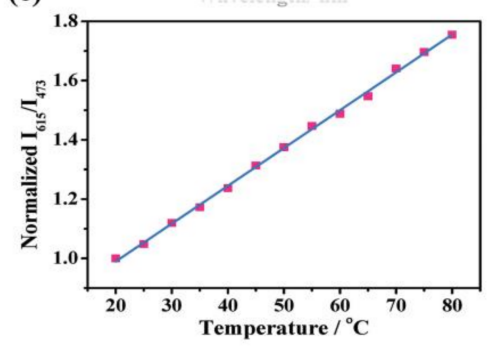

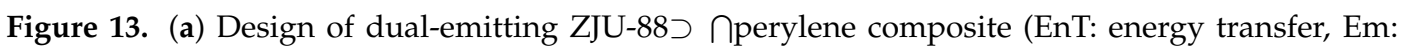

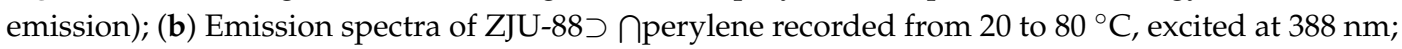
(c) Temperature-dependent intensity ratio of $\mathrm{Eu}^{3+}(615 \mathrm{~nm})$ to perylene $(473 \mathrm{~nm})$ and the fitted curve

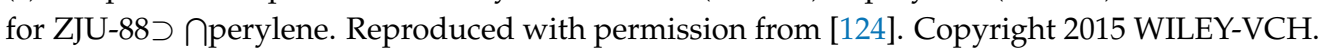

\subsection{LnMOFs for Biosensing}

Nitrofurans are a type of extensively used veterinary antibiotics effective for the treatment of protozoan and bacterial infections in human beings. It is, however, still urgently needed, as ell as very challenging to develop a rapid and effective approach to detect nitrofuran antibiotics (NFAs) [125]. Yang and coworkers fabricated a Eu-BCA $\left(\left\{\left[\mathrm{Eu}_{2}(\mathrm{BCA})_{3}\left(\mathrm{H}_{2} \mathrm{O}\right)(\mathrm{DMF})_{3}\right] \cdot 0.5 \mathrm{DMF} \cdot \mathrm{H}_{2} \mathrm{O}\right\}_{\mathrm{n}}\right.$, $\mathrm{BCA}=2,2^{\prime}$-biquinoline-4,4'-dicarboxylate) thin-film sensor for NFAs by coating a cost-effective stainless-steel wire mesh using the $\mathrm{Co}_{3} \mathrm{O}_{4}$ nano-anchor fixation approach. The Eu-BCA thin-film sensor shows significant quenching effect for NFAs owing to the synergistic effect of electron-transfer and the inner-filter effect. It furthermore shows high selectivity and sensitivity to NFAs with detection limits of 0.21 and $0.16 \mathrm{~mm}$ for nitrofurantoin (NFT) and nitrofurazone (NFZ), respectively. NFAs were also successfully detected in real samples, indicating the potential of this Eu-BCA thin-film for biosensing [126].

Another pharmaceutical sensor was designed by Wang and coworkers based on a luminescent mixed-crystal LnMOF (MLMOF-3 $=\mathrm{Eu}_{0.1} \mathrm{~Tb}_{0.9}$-BTC) thin film [127]. The uniform and continuous thin film was prepared by coating the monodisperse nanoscale MLMOF-3 on indium-tin-oxide (ITO) glass (Figure 14a,b). The luminescence intensity ratios of $\mathrm{Eu}^{3+}$ at $619 \mathrm{~nm}$ to $\mathrm{Tb}^{3+}$ at $547 \mathrm{~nm}$ of the MLMOF-3 film were used to calculate the intensity ratio change by $\left(R-R_{0}\right) / R_{0}$, where $R_{0}$ is the initial intensity ratio without the analyte, and $\mathrm{R}$ is the intensity ratio upon the addition of the analyte (Figure 14c). The luminescence intensity depended significantly on several pharmaceutical molecules (such as antipyrine, benzafibrate, caffeine, clofibrate, clotetracycline, coumarin, diclofenac, fluorouracil, nalidixic acid, naproxen, sulfachinoxalin, and tetracycline) Moreover, the MLMOF-3 thin film shows different guest-dependent colors that can intuitively be distinguished by the naked eye (Figure 14d,e). The authors presumed that the different functional groups and structures of these pharmaceutical molecules may not only modulate the antenna effect between organic linkers and $\mathrm{Ln}^{3+}$ ions but also affect energy transfer between $\mathrm{Tb}^{3+}$ and $\mathrm{Eu}^{3+}$, causing the different luminescent changes in the MLMOF-3 thin film. These results demonstrate that the mixed LnMOF film can be used as luminescence sensors for different pharmaceutical molecules. 
(a)

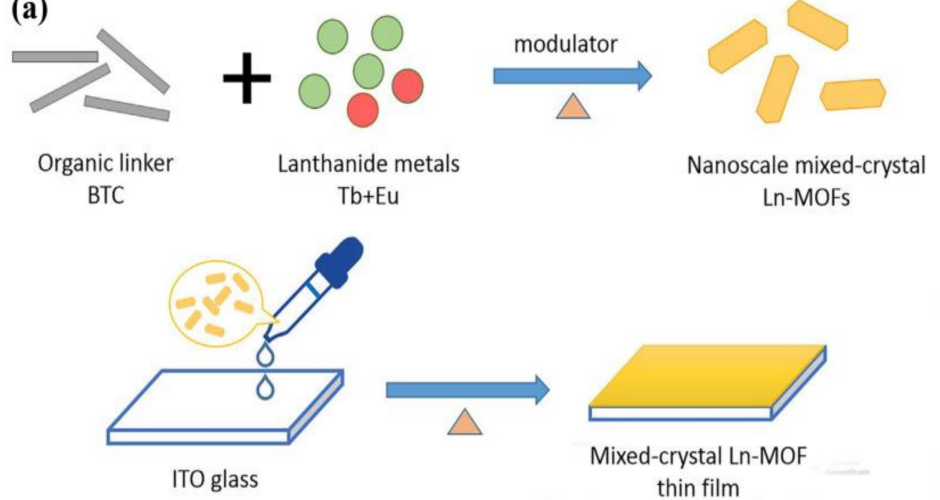

(c)

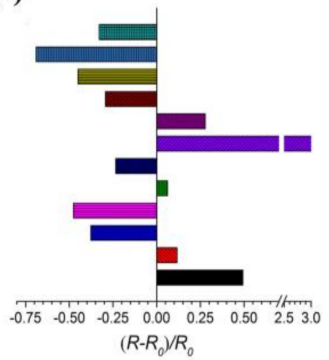

(d)

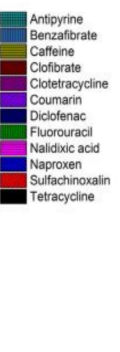

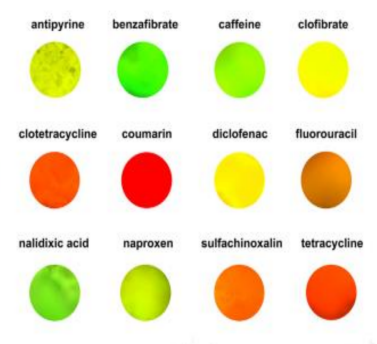

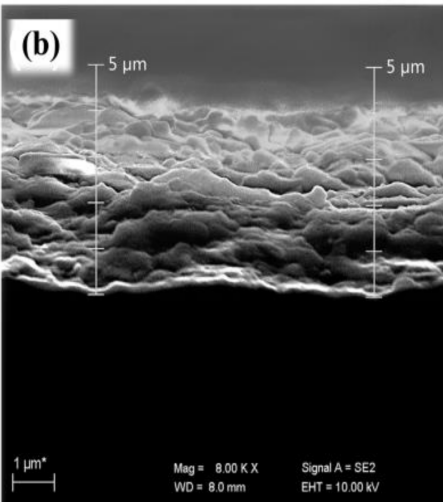

(e)

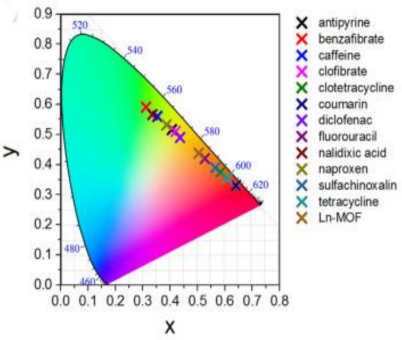

Figure 14. (a) Preparation process of mixed-crystal LnMOF thin film; (b) SEM image of cross-section of the film; (c) the emission intensity ratio changes; (d) the optical photographs; and (e) CIE chromaticity coordinates of the LnMOF thin film in the presence of different analytes. $\left(20 \mathrm{~mL}, 10^{-4} \mathrm{M}\right)$. Reproduced with permission from [127]. Copyright 2017 Elsevier B.V.

Yan and coworkers were the first to design a diagnosis platform for vinyl chloride carcinogen based on a $3 \mathrm{~d}-4 \mathrm{f}-4 \mathrm{~d}$ heterometallic $\mathrm{MOF}\left(\mathrm{Eu}^{3+} / \mathrm{Cu}^{2+}-\mathrm{Zr}_{6} \mathrm{O}_{4}(\mathrm{OH})_{4}\left(\mathrm{O}_{2} \mathrm{C}-\mathrm{C}_{6} \mathrm{H}_{2}-\mathrm{CO}_{2}\right.\right.$ $\left.\left(\mathrm{CO}_{2} \mathrm{H}\right)_{2}\right)_{6} \cdot x \mathrm{H}_{2} \mathrm{O}$ ) [128]. The nanoprobe exhibits high selectivity to thiodiglycolic acid (TDGA) with a luminescence enhancement of about 27.5-fold, the main metabolite of vinyl chloride monomer (VCM) in human urine. It further shows a fast response to TDGA within $4 \mathrm{~min}$ and impressive sensitivity with a detection limit of $89 \mathrm{ng} \cdot \mathrm{mL}^{-1}$ without interference of other coexisting species in urine. Such excellent sensing performance enables it to monitor TDGA levels in human urine. Furthermore, a portable urine dipstick based on the sensor has been developed to conveniently evaluate individual's intoxication degree of VCM.

\section{Conclusions and Outlook}

This comprehensive review covers the recent research progress on luminescent lanthanide MOFs and their applications in sensing cations, anions, small molecules, nitroaromatic explosives, gases, vapors, $\mathrm{pH}$, temperature, and biomolecules. The sensing functionality of LnMOF probes is based on their luminescence changes in response to different analytes, all recognizable by means of spectrofluorometry or the naked eye. Most of the luminescent LnMOF sensors operate by a turn-off mechanism when detecting electron acceptors in which luminescence is quenched through both the electron and the energy transfer between LnMOF sensors and analytes. However, the turn-on detection mode with higher sensitivity and lower detection limits has also been implemented in luminescence-based LnMOF sensors resulting in luminescence enhancement or wavelength shifts. Furthermore, rational incorporation of the functional sites (e.g., Lewis acidic or basic sites and open metal sites) on the pores of the LnMOFs has made them very promising sensors to detect target compounds. Moreover, the ratiometric sensing approach has easily been achieved by embedding 
multi-luminescent motifs onto the frameworks, which can overcome the main drawbacks of the intensity-based measurements with only one transition.

Although the sensing behavior of LnMOFs has been studied comprehensively, some problems remain. While many investigations have shown excellent results for sensing hazardous materials, fast detection of nitroexplosives with a handheld device in public places, such as the airport and railway station, stays challenging. Furthermore, nanoscale luminescent MOFs with controllable size and morphology are very promising in applications for sensing in living cells. More efforts should be devoted to integrating different functionalities such as cellular sensing and imaging and molecular targeting, as well as drug delivery for practical applications in theranostic nanomedicine. Moreover, in-depth studies on the relationships between structure and luminescent behavior must be conducted using theoretical methods. In addition, the stabilities of recycling, material cost, and portability for practical applications need further improvement. With constant efforts being made to handle these challenges, we believe that the LnMOFs definitely hold a bright future in the field of luminescence sensing.

Acknowledgments: This research has been made possible by a postdoctoral scholarship of the Ghent University Special Research Fund (ref. number: BOF.PDO.2016.0030.01). G.W. would like to thank the Chinese Scholarship Council and UGENT-BOF grant for financial support.

Conflicts of Interest: The authors declare no conflict of interest.

\section{Abbreviations}

\begin{tabular}{|c|c|}
\hline Ad & adenine \\
\hline BCA & $2,2^{\prime}$-biquinoline- $4,4^{\prime}$-dicarboxylate \\
\hline $\mathrm{H}_{2} \mathrm{BDC}$ & 1,4-benzenedicarboxylic acid \\
\hline $\mathrm{H}_{2} \mathrm{BDC}-\mathrm{F}_{4}$ & 2,3,5,6-tetrafluoro-1,4-benzenedicarboxylate \\
\hline bipy & 4,4'-bipyridine \\
\hline $\mathrm{H}_{2} \mathrm{BPDC}$ & 2,2'-bipyridine-3,3'-dicarboxylic acid \\
\hline BPT & biphenyl-3,4',5-tricarboxylate \\
\hline bpydc & 2,2'-bipyridine- $5,5^{\prime}$-dicarboxylic acid \\
\hline $\mathrm{H}_{3} \mathrm{BTB}$ & 1,3,5-benzenetribenzoate \\
\hline BTC & benzene-1,3,5- tricarboxylate \\
\hline $\mathrm{H}_{4}$ btec & pyromellitic acid \\
\hline $\mathrm{H}_{4} \mathrm{BTMIPA}$ & 5,5'-methylenebis(2,4,6-trimethylisophthalic acid) \\
\hline $\mathrm{CB}$ & conduction band \\
\hline CDs & carbon dots \\
\hline $\mathrm{HCHO}$ & formaldehyde \\
\hline CPNPs & coordination polymer nanoparticles \\
\hline $\mathrm{H}_{2} \mathrm{CPOC}$ & 5-(4'-carboxylphenoxy) nicotinic acid \\
\hline DMA & dimethylacetamide \\
\hline DMBDC & 2,5-dimethoxy-1,4-benzenedicarboxylate \\
\hline DMF & $\mathrm{N}^{\prime} \mathrm{N}$-dimethylformamide \\
\hline DPA & dipicolinic acid \\
\hline $\mathrm{H}_{2} \mathrm{FDC}$ & 9,9-dimethyl-2,7-fluorenedicarboxylic acid \\
\hline FBPT & $2^{\prime}$-fluoro-biphenyl-3, $4^{\prime}, 5$-tricarboxylate \\
\hline FTIR & Fourier-transform infrared spectroscopy \\
\hline fum & fumarate \\
\hline ICT & intramolecular-charge-transfer \\
\hline $\mathrm{H}_{2} \mathrm{ipbpBr}$ & 1-(3,5-dicarboxyphenyl)-4, $4^{\prime}$-bipyridinium bromid \\
\hline ITO & indium-tin-oxide \\
\hline $\mathrm{H}_{2} \mathrm{~L}_{1}$ & 2,5-di(pyridin-4-yl)terephthalic acid \\
\hline $\mathrm{H}_{2} \mathrm{~L}_{2}^{-}$ & 3, 5-dicarboxy-phenol anion ligand \\
\hline $\mathrm{L}_{3}$ & $4,4^{\prime}$-dicarboxylate- $2,2^{\prime}$-dipyridine anion \\
\hline
\end{tabular}




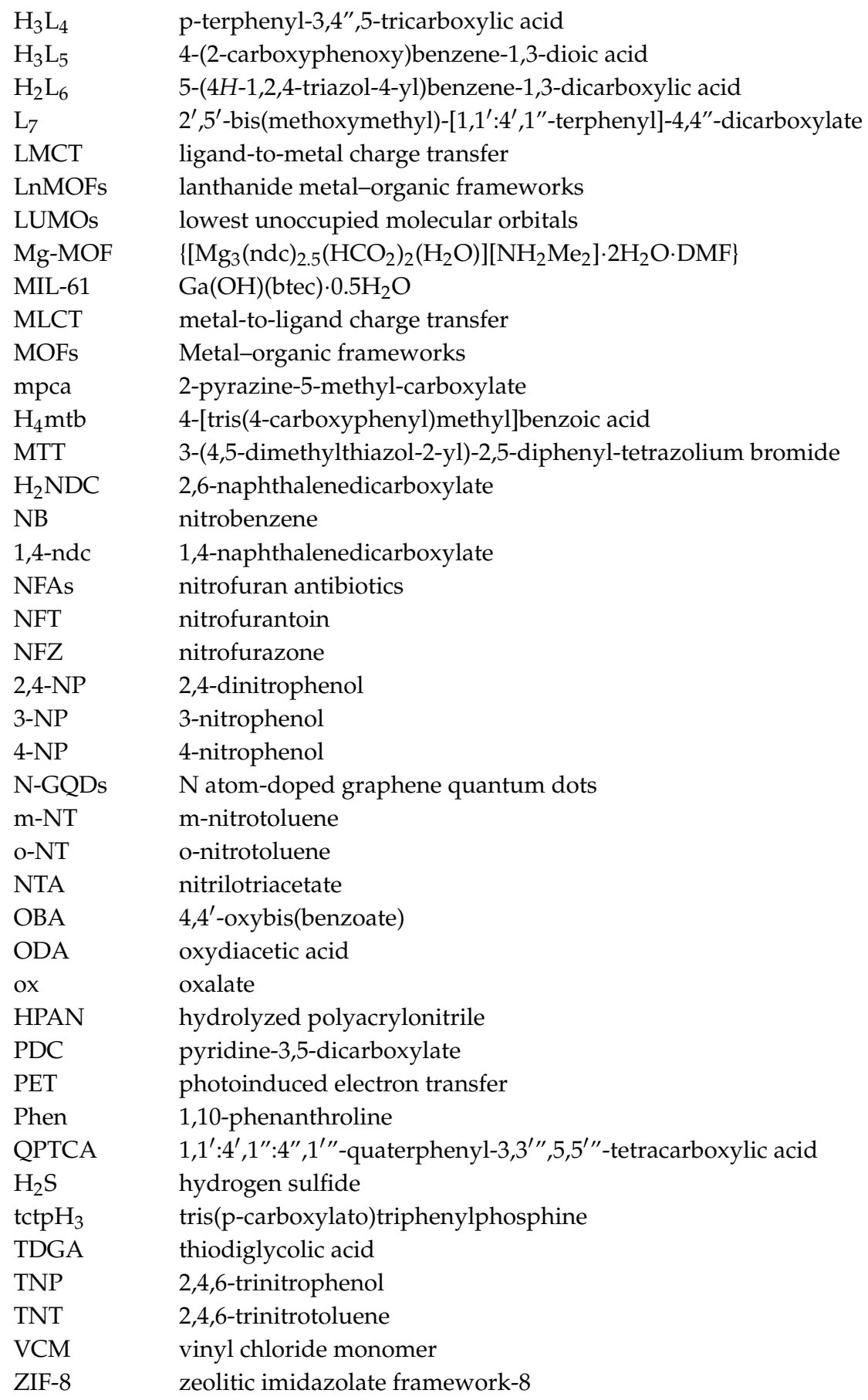

\section{References}

1. Colon, Y.J.; Snurr, R.Q. High-throughput computational screening of metal-organic frameworks. Chem. Soc. Rev. 2014, 43, 5735-5749. [CrossRef] [PubMed]

2. Zhao, X.; Bu, X.; Nguyen, E.T.; Zhai, Q.G.; Mao, C.; Feng, P. Multivariable Modular Design of Pore Space Partition. J. Am. Chem. Soc. 2016, 138, 15102-15105. [CrossRef] [PubMed]

3. He, Y.; Zhou, W.; Qian, G.; Chen, B. Methane storage in metal-organic frameworks. Chem. Soc. Rev. 2014, 43, 5657-5678. [CrossRef] [PubMed]

4. Flaig, R.W.; Osborn Popp, T.M.; Fracaroli, A.M.; Kapustin, E.A.; Kalmutzki, M.J.; Altamimi, R.M.; Fathieh, F.; Reimer, J.A.; Yaghi, O.M. The Chemistry of $\mathrm{CO}_{2}$ Capture in an Amine-Functionalized Metal-Organic Framework under Dry and Humid Conditions. J. Am. Chem. Soc. 2017, 139, 12125-12128. [CrossRef] [PubMed] 
5. Medishetty, R.; Nalla, V.; Nemec, L.; Henke, S.; Mayer, D.; Sun, H.; Reuter, K.; Fischer, R.A. A New Class of Lasing Materials: Intrinsic Stimulated Emission from Nonlinear Optically Active Metal-Organic Frameworks. Adv. Mater. 2017, 29, 1605637. [CrossRef] [PubMed]

6. Zhu, M.; Hao, Z.M.; Song, X.Z.; Meng, X.; Zhao, S.N.; Song, S.Y.; Zhang, H.J. A new type of double-chain based 3D lanthanide(III) metal-organic framework demonstrating proton conduction and tunable emission. Chem. Commun. 2014, 50, 1912-1914. [CrossRef] [PubMed]

7. Nguyen, C.V.; Liao, Y.-T.; Kang, T.-C.; Chen, J.E.; Yoshikawa, T.; Nakasaka, Y.; Masuda, T.; Wu, K.C.W. A metal-free, high nitrogen-doped nanoporous graphitic carbon catalyst for an effective aerobic HMF-to-FDCA conversion. Green Chem. 2016, 18, 5957-5961. [CrossRef]

8. Fan, S.; Dong, W.; Huang, X.; Gao, H.; Wang, J.; Jin, Z.; Tang, J.; Wang, G. In Situ-Induced Synthesis of Magnetic Cu-CuFe ${ }_{2} \mathrm{O}_{4} @$ HKUST-1 Heterostructures with Enhanced Catalytic Performance for Selective Aerobic Benzylic C-H Oxidation. ACS Catal. 2016, 7, 243-249. [CrossRef]

9. Du, P.-Y.; Gu, W.; Liu, X. A three-dimensional Nd(III)-based metal-organic framework as a smart drug carrier. New J. Chem. 2016, 40, 9017-9020. [CrossRef]

10. Vallejo, J.; Fortea-Pérez, F.R.; Pardo, E.; Benmansour, S.; Castro, I.; Krzystek, J.; Armentano, D.; Cano, J. Guest-dependent single-ion magnet behaviour in a cobalt(II) metal-organic framework. Chem. Sci. 2016, 7, 2286-2293. [CrossRef]

11. Zhao, S.N.; Song, X.Z.; Zhu, M.; Meng, X.; Wu, L.L.; Feng, J.; Song, S.Y.; Zhang, H.J. Encapsulation of Ln(III) Ions/Dyes within a Microporous Anionic MOF by Post-synthetic Ionic Exchange Serving as a Ln(III) Ion Probe and Two-Color Luminescent Sensors. Chem. Eur. J. 2015, 21, 9748-9752. [CrossRef] [PubMed]

12. Wales, D.J.; Grand, J.; Ting, V.P.; Burke, R.D.; Edler, K.J.; Bowen, C.R.; Mintova, S.; Burrows, A.D. Gas sensing using porous materials for automotive applications. Chem. Soc. Rev. 2015, 44, 4290-4321. [CrossRef] [PubMed]

13. Hao, Z.; Yang, G.; Song, X.; Zhu, M.; Meng, X.; Zhao, S.; Song, S.; Zhang, H. A europium(III) based metal-organic framework: Bifunctional properties related to sensing and electronic conductivity. J. Mater. Chem. A 2014, 2, 237-244. [CrossRef]

14. Niu, S.; Wang, Z.; Zhou, T.; Yu, M.; Yu, M.; Qiu, J. A Polymetallic Metal-Organic Framework-Derived Strategy toward Synergistically Multidoped Metal Oxide Electrodes with Ultralong Cycle Life and High Volumetric Capacity. Adv. Funct. Mater. 2017, 27, 1605332. [CrossRef]

15. Zhao, S.-N.; Song, X.-Z.; Song, S.-Y.; Zhang, H.-J. Highly efficient heterogeneous catalytic materials derived from metal-organic framework supports/precursors. Coord. Chem. Rev. 2017, 337, 80-96. [CrossRef]

16. Salunkhe, R.R.; Kaneti, Y.V.; Kim, J.; Kim, J.H.; Yamauchi, Y. Nanoarchitectures for Metal-Organic Framework-Derived Nanoporous Carbons toward Supercapacitor Applications. Acc. Chem. Res. 2016, 49, 2796-2806. [CrossRef] [PubMed]

17. Yan, H.; Hohman, J.N.; Li, F.H.; Jia, C.; Solis-Ibarra, D.; Wu, B.; Dahl, J.E.; Carlson, R.M.; Tkachenko, B.A.; Fokin, A.A.; et al. Hybrid metal-organic chalcogenide nanowires with electrically conductive inorganic core through diamondoid-directed assembly. Nat. Mater. 2017, 16, 349-355. [CrossRef] [PubMed]

18. Liu, S.; Yue, Z.; Liu, Y. Incorporation of imidazole within the metal-organic framework UiO-67 for enhanced anhydrous proton conductivity. Dalton Trans. 2015, 44, 12976-12980. [CrossRef] [PubMed]

19. Li, Y.; Tang, J.; He, L.; Liu, Y.; Liu, Y.; Chen, C.; Tang, Z. Core-Shell Upconversion Nanoparticle@MetalOrganic Framework Nanoprobes for Luminescent/Magnetic Dual-Mode Targeted Imaging. Adv. Mater. 2015, 27, 4075-4080. [CrossRef] [PubMed]

20. Cui, Y.; Yue, Y.; Qian, G.; Chen, B. Luminescent functional metal-organic frameworks. Chem. Rev. 2012, 112, 1126-1162. [CrossRef] [PubMed]

21. Wang, C.; Zhang, T.; Lin, W. Rational synthesis of noncentrosymmetric metal-organic frameworks for second-order nonlinear optics. Chem. Rev. 2012, 112, 1084-1104. [CrossRef] [PubMed]

22. Hao, Z.; Song, X.; Zhu, M.; Meng, X.; Zhao, S.; Su, S.; Yang, W.; Song, S.; Zhang, H. One-dimensional channel-structured Eu-MOF for sensing small organic molecules and $\mathrm{Cu}^{2+}$ ion. J. Mater. Chem. A 2013, 1, 11043-11050. [CrossRef]

23. Liu, W.; Huang, X.; Xu, C.; Chen, C.; Yang, L.; Dou, W.; Chen, W.; Yang, H.; Liu, W. A Multi-responsive Regenerable Europium-Organic Framework Luminescent Sensor for $\mathrm{Fe}^{3+}, \mathrm{Cr}^{\mathrm{VI}}$ Anions, and Picric Acid. Chem. Eur. J. 2016, 22, 18769-18776. [CrossRef] [PubMed] 
24. Wu, J.X.; Yan, B. Eu(III)-functionalized In-MOF ( $\operatorname{In}(\mathrm{OH})$ bpydc) as fluorescent probe for highly selectively sensing organic small molecules and anions especially for $\mathrm{CHCl}_{3}$ and $\mathrm{MnO}_{4}$. J. Colloid Interface Sci. 2017, 504, 197-205. [CrossRef] [PubMed]

25. Sun, N.-N.; Yan, B. Rapid and facile ratiometric detection of $\mathrm{CO}_{3}{ }^{2-}$ based on heterobimetallic metal-organic frameworks (Eu/Pt-MOFs). Dyes Pigment. 2017, 142, 1-7. [CrossRef]

26. Kreno, L.E.; Leong, K.; Farha, O.K.; Allendorf, M.; Van Duyne, R.P.; Hupp, J.T. Metal-organic framework materials as chemical sensors. Chem. Rev. 2012, 112, 1105-1125. [CrossRef] [PubMed]

27. Kang, X.M.; Cheng, R.R.; Xu, H.; Wang, W.M.; Zhao, B. A Sensitive Luminescent Acetylacetone Probe Based on Zn-MOF with Six-Fold Interpenetration. Chem. Eur. J. 2017, 23, 13289-13293. [CrossRef] [PubMed]

28. Cui, Y.; Chen, B.; Qian, G. Lanthanide metal-organic frameworks for luminescent sensing and light-emitting applications. Coord. Chem. Rev. 2014, 273-274, 76-86. [CrossRef]

29. Zhao, S.-N.; Wu, L.-L.; Feng, J.; Song, S.-Y.; Zhang, H.-J. An ideal detector composed of a 3D Gd-based coordination polymer for DNA and $\mathrm{Hg}^{2+}$ ion. Inorg. Chem. Front. 2016, 3, 376-380. [CrossRef]

30. Doonan, C.; Ricco, R.; Liang, K.; Bradshaw, D.; Falcaro, P. Metal-Organic Frameworks at the Biointerface: Synthetic Strategies and Applications. Acc. Chem. Res. 2017, 50, 1423-1432. [CrossRef] [PubMed]

31. Roales, J.; Moscoso, F.G.; Gamez, F.; Lopes-Costa, T.; Sousaraei, A.; Casado, S.; Castro-Smirnov, J.R.; Cabanillas-Gonzalez, J.; Almeida, J.; Queiros, C.; et al. Preparation of Luminescent Metal-Organic Framework Films by Soft-Imprinting for 2,4-Dinitrotoluene Sensing. Materials 2017, 10, 992. [CrossRef] [PubMed]

32. Lustig, W.P.; Mukherjee, S.; Rudd, N.D.; Desai, A.V.; Li, J.; Ghosh, S.K. Metal-organic frameworks: Functional luminescent and photonic materials for sensing applications. Chem. Soc. Rev. 2017, 46, 3242-3285. [CrossRef] [PubMed]

33. Yang, X.-L.; Chen, X.; Hou, G.-H.; Guan, R.-F.; Shao, R.; Xie, M.-H. A Multiresponsive Metal-Organic Framework: Direct Chemiluminescence, Photoluminescence, and Dual Tunable Sensing Applications. Adv. Funct. Mater. 2016, 26, 393-398. [CrossRef]

34. Chen, Y.; Wang, B.; Wang, X.; Xie, L.H.; Li, J.; Xie, Y.; Li, J.R. A Copper(II)-Paddlewheel Metal-Organic Framework with Exceptional Hydrolytic Stability and Selective Adsorption and Detection Ability of Aniline in Water. ACS Appl. Mater. Interfaces 2017, 9, 27027-27035. [CrossRef] [PubMed]

35. Wang, D.; Liu, J.; Liu, Z. A chemically stable europium metal-organic framework for bifunctional chemical sensor and recyclable on-off-on vapor response. J. Solid State Chem. 2017, 251, 243-247. [CrossRef]

36. Wang, J.; Li, Y.; Jiang, M.; Liu, Y.; Zhang, L.; Wu, P. A Highly Chemically Stable Metal-Organic Framework as a Luminescent Probe for the Regenerable Ratiometric Sensing of pH. Chem. Eur. J. 2016, 22, 13023-13027. [CrossRef] [PubMed]

37. Cui, Y.; Xu, H.; Yue, Y.; Guo, Z.; Yu, J.; Chen, Z.; Gao, J.; Yang, Y.; Qian, G.; Chen, B. A luminescent mixed-lanthanide metal-organic framework thermometer. J. Am. Chem. Soc. 2012, 134, 3979-3982. [CrossRef] [PubMed]

38. Wang, H.; Zhao, D.; Cui, Y.; Yang, Y.; Qian, G. A Eu/Tb-mixed MOF for luminescent high-temperature sensing. J. Solid State Chem. 2017, 246, 341-345. [CrossRef]

39. Rao, X.; Song, T.; Gao, J.; Cui, Y.; Yang, Y.; Wu, C.; Chen, B.; Qian, G. A highly sensitive mixed lanthanide metal-organic framework self-calibrated luminescent thermometer. J. Am. Chem. Soc. 2013, 135, 15559-15564. [CrossRef] [PubMed]

40. Zhang, Y.; Li, G.; Geng, D.; Shang, M.; Peng, C.; Lin, J. Color-tunable emission and energy transfer in $\mathrm{Ca}_{3} \mathrm{Gd}_{7}\left(\mathrm{PO}_{4}\right)\left(\mathrm{SiO}_{4}\right)_{5} \mathrm{O}_{2}: \mathrm{Ce}^{3+} / \mathrm{Tb}^{3+} / \mathrm{Mn}^{2+}$ phosphors. Inorg. Chem. 2012, 51, 11655-11664. [CrossRef] [PubMed]

41. Zhang, Y.; Geng, D.; Kang, X.; Shang, M.; Wu, Y.; Li, X.; Lian, H.; Cheng, Z.; Lin, J. Rapid, large-scale, morphology-controllable synthesis of YOF: $\operatorname{Ln}^{3+}(\mathrm{Ln}=\mathrm{Tb}, \mathrm{Eu}, \mathrm{Tm}, \mathrm{Dy}, \mathrm{Ho}, \mathrm{Sm})$ nano-/microstructures with multicolor-tunable emission properties. Inorg. Chem. 2013, 52, 12986-12994. [CrossRef] [PubMed]

42. Zhang, Y.; Li, X.; Li, K.; Lian, H.; Shang, M.; Lin, J. Crystal-site engineering control for the reduction of Eu ${ }^{3+}$ to $\mathrm{Eu}^{2+}$ in $\mathrm{CaYAlO}_{4}$ : Structure refinement and tunable emission properties. ACS Appl. Mater. Interfaces 2015, 7, 2715-2725. [CrossRef] [PubMed]

43. Mao, J. Structures and luminescent properties of lanthanide phosphonates. Coord. Chem. Rev. 2007, 251, 1493-1520. [CrossRef]

44. Song, J.L.; Mao, J.G. New types of blue, red or near IR luminescent phosphonate-decorated lanthanide oxalates. Chem. Eur. J. 2005, 11, 1417-1424. [CrossRef] [PubMed] 
45. Parmentier, A.B.; Smet, P.F.; Poelman, D. Broadband Luminescence in Rare Earth Doped $\mathrm{Sr}_{2} \mathrm{SiS}_{4}$ : Relating Energy Levels of $\mathrm{Ce}^{3+}$ and $\mathrm{Eu}^{2+}$. Materials 2013, 6, 3663-3675. [CrossRef] [PubMed]

46. Binnemans, K. Lanthanide-based luminescent hybrid materials. Chem. Rev. 2009, 109, 4283-4374. [CrossRef] [PubMed]

47. Choppin, G.R.; Peterman, D.R. Applications of lanthanide luminescence spectroscopy to solution studies of coordination chemistry. Coord. Chem. Rev. 1998, 174, 283-299. [CrossRef]

48. Moore, E.G.; Samuel, A.P.S.; Raymond, K.N. From Antenna to Assay: Lessons Learned in Lanthanide Luminescence. Acc. Chem. Res. 2009, 42, 542-552. [CrossRef] [PubMed]

49. Bünzli, J.-C.G. Lanthanide Luminescence for Biomedical Analyses and Imaging. Chem. Rev. 2010, 110, 2729-2755. [CrossRef] [PubMed]

50. Eliseeva, S.V.; Bunzli, J.C. Lanthanide luminescence for functional materials and bio-sciences. Chem. Soc. Rev. 2010, 39, 189-227. [CrossRef] [PubMed]

51. Bunzli, J.C.; Piguet, C. Taking advantage of luminescent lanthanide ions. Chem. Soc. Rev. 2005, 34, $1048-1077$. [CrossRef] [PubMed]

52. Xu, L.-J.; Xu, G.-T.; Chen, Z.-N. Recent advances in lanthanide luminescence with metal-organic chromophores as sensitizers. Coord. Chem. Rev. 2014, 273-274, 47-62. [CrossRef]

53. Weng, H.; Yan, B. N-GQDs and $\mathrm{Eu}^{3+}$ co-encapsulated anionic MOFs: Two-dimensional luminescent platform for decoding benzene homologues. Dalton Trans. 2016, 45, 8795-8801. [CrossRef] [PubMed]

54. Parker, D. Luminescent lanthanide sensors for $\mathrm{pH}, \mathrm{O}_{2}$ and selected anions. Coord. Chem. Rev. 2000, 205, 109-130. [CrossRef]

55. Sun, Y.-G.; Gu, X.-F.; Ding, F.; Smet, P.F.; Gao, E.-J.; Poelman, D.; Verpoort, F. Synthesis, Crystal Structures, and Properties of Novel Heterometallic $\mathrm{La} / \mathrm{Pr}-\mathrm{Cu}-\mathrm{K}$ and $\mathrm{Sm} / \mathrm{Eu} / \mathrm{Tb}-\mathrm{Cu}$ Coordination Polymers. Cryst. Growth Des. 2010, 10, 1059-1067. [CrossRef]

56. Liu, D.; Lu, K.; Poon, C.; Lin, W. Metal-organic frameworks as sensory materials and imaging agents. Inorg. Chem. 2014, 53, 1916-1924. [CrossRef] [PubMed]

57. Yi, F.-Y.; Chen, D.; Wu, M.-K.; Han, L.; Jiang, H.-L. Chemical Sensors Based on Metal-Organic Frameworks. ChemPlusChem 2016, 81, 675-690. [CrossRef]

58. Gaetke, L.M.; Chow-Johnson, H.S.; Chow, C.K. Copper: Toxicological relevance and mechanisms. Arch. Toxicol. 2014, 88, 1929-1938. [CrossRef] [PubMed]

59. Song, Y.; Qu, K.; Xu, C.; Ren, J.; Qu, X. Visual and quantitative detection of copper ions using magnetic silica nanoparticles clicked on multiwalled carbon nanotubes. Chem. Commun. 2010, 46, 6572-6574. [CrossRef] [PubMed]

60. Wen, R.M.; Han, S.D.; Ren, G.J.; Chang, Z.; Li, Y.W.; Bu, X.H. A flexible zwitterion ligand based lanthanide metal-organic framework for luminescence sensing of metal ions and small molecules. Dalton Trans. 2015, 44, 10914-10917. [CrossRef] [PubMed]

61. Song, C.; Yang, W.; Zhou, N.; Qian, R.; Zhang, Y.; Lou, K.; Wang, R.; Wang, W. Fluorescent theranostic agents for $\mathrm{Hg}^{2+}$ detection and detoxification treatment. Chem. Commun. 2015, 51, 4443-4446. [CrossRef] [PubMed]

62. Liu, T.; Che, J.X.; Hu, Y.Z.; Dong, X.W.; Liu, X.Y.; Che, C.M. Alkenyl/thiol-derived metal-organic frameworks (MOFs) by means of postsynthetic modification for effective mercury adsorption. Chem. Eur. J. 2014, 20, 14090-14095. [CrossRef] [PubMed]

63. Chen, B.; Wang, L.; Xiao, Y.; Fronczek, F.R.; Xue, M.; Cui, Y.; Qian, G. A luminescent metal-organic framework with Lewis basic pyridyl sites for the sensing of metal ions. Angew Chem. Int. Ed. 2009, 48, 500-503. [CrossRef] [PubMed]

64. Liu, B.; Hou, L.; Wu, W.P.; Dou, A.N.; Wang, Y.Y. Highly selective luminescence sensing for $\mathrm{Cu}^{2+}$ ions and selective $\mathrm{CO}_{2}$ capture in a doubly interpenetrated MOF with Lewis basic pyridyl sites. Dalton Trans. 2015, 44, 4423-4427. [CrossRef] [PubMed]

65. Tang, Q.; Liu, S.; Liu, Y.; Miao, J.; Li, S.; Zhang, L.; Shi, Z.; Zheng, Z. Cation sensing by a luminescent metal-organic framework with multiple Lewis basic sites. Inorg. Chem. 2013, 52, 2799-2801. [CrossRef] [PubMed]

66. Hou, S.; Liu, Q.K.; Ma, J.P.; Dong, Y.B. Cd(II)-coordination framework: Synthesis, anion-induced structural transformation, anion-responsive luminescence, and anion separation. Inorg. Chem. 2013, 52, 3225-3235. [CrossRef] [PubMed] 
67. Wu, Y.; Yang, G.P.; Zhao, Y.; Wu, W.P.; Liu, B.; Wang, Y.Y. Three new solvent-directed Cd(II)-based MOFs with unique luminescent properties and highly selective sensors for $\mathrm{Cu}^{2+}$ cations and nitrobenzene. Dalton Trans. 2015, 44, 3271-3277. [CrossRef] [PubMed]

68. Wen, G.X.; Wu, Y.P.; Dong, W.W.; Zhao, J.; Li, D.S.; Zhang, J. An Ultrastable Europium(III)-Organic Framework with the Capacity of Discriminating $\mathrm{Fe}^{2+} / \mathrm{Fe}^{3+}$ Ions in Various Solutions. Inorg. Chem. 2016, 55, 10114-10117. [CrossRef] [PubMed]

69. Weng, H.; Yan, B. A Eu(III) doped metal-organic framework conjugated with fluorescein-labeled single-stranded DNA for detection of $\mathrm{Cu}(\mathrm{II})$ and sulfide. Anal. Chim. Acta 2017, 988, 89-95. [CrossRef] [PubMed]

70. Yan, W.; Zhang, C.; Chen, S.; Han, L.; Zheng, H. Two Lanthanide Metal-Organic Frameworks as Remarkably Selective and Sensitive Bifunctional Luminescence Sensor for Metal Ions and Small Organic Molecules. ACS Appl. Mater. Interfaces 2017, 9, 1629-1634. [CrossRef] [PubMed]

71. Chen, Z.; Sun, Y.; Zhang, L.; Sun, D.; Liu, F.; Meng, Q.; Wang, R.; Sun, D. A tubular europium-organic framework exhibiting selective sensing of $\mathrm{Fe}^{3+}$ and $\mathrm{Al}^{3+}$ over mixed metal ions. Chem. Commun. 2013, 49, 11557-11559. [CrossRef] [PubMed]

72. Tan, H.; Liu, B.; Chen, Y. Lanthanide Coordination Polymer Nanoparticles for Sensing of Mercury(II) by Photoinduced Electron Transfer. ACS Nano 2012, 6, 10505-10511. [CrossRef] [PubMed]

73. Li, L.; Chen, Q.; Niu, Z.; Zhou, X.; Yang, T.; Huang, W. Lanthanide metal-organic frameworks assembled from a fluorene-based ligand: Selective sensing of $\mathrm{Pb}^{2+}$ and $\mathrm{Fe}^{3+}$ ions. J. Mater. Chem. C 2016, 4, 1900-1905. [CrossRef]

74. Ji, G.; Liu, J.; Gao, X.; Sun, W.; Wang, J.; Zhao, S.; Liu, Z. A luminescent lanthanide MOF for selectively and ultra-high sensitively detecting $\mathrm{Pb}^{2+}$ ions in aqueous solution. J. Mater. Chem. A 2017, 5, 10200-10205. [CrossRef]

75. Sun, N.; Yan, B. $\mathrm{Ag}^{+}$-induced photoluminescence enhancement in lanthanide post-functionalized MOFs and $\mathrm{Ag}^{+}$sensing. Phys. Chem. Chem. Phys. 2017, 19, 9174-9180. [CrossRef] [PubMed]

76. Mahata, P.; Mondal, S.K.; Singha, D.K.; Majee, P. Luminescent rare-earth-based MOFs as optical sensors. Dalton Trans. 2017, 46, 301-328. [CrossRef] [PubMed]

77. Wang, D.; Fan, J.; Shang, M.; Li, K.; Zhang, Y.; Lian, H.; Lin, J. Pechini-type sol-gel synthesis and multicolor-tunable emission properties of $\mathrm{GdY}\left(\mathrm{MoO}^{4}\right)_{3}: \mathrm{RE}^{3+}(\mathrm{RE}=\mathrm{Eu}, \mathrm{Dy}, \mathrm{Sm}, \mathrm{Tb})$ phosphors. Opt. Mater. 2016, 51, 162-170. [CrossRef]

78. Chen, B.; Wang, L.; Zapata, F.; Qian, G.; Lobkovsky, E.B. A Luminescent Microporous Metal-Organic Framework for the Recognition and Sensing of Anions. J. Am. Chem. Soc. 2008, 130, 6718-6719. [CrossRef] [PubMed]

79. Zhou, J.M.; Shi, W.; Xu, N.; Cheng, P. Highly selective luminescent sensing of fluoride and organic small-molecule pollutants based on novel lanthanide metal-organic frameworks. Inorg. Chem. 2013, 52, 8082-8090. [CrossRef] [PubMed]

80. Shi, P.F.; Hu, H.C.; Zhang, Z.Y.; Xiong, G.; Zhao, B. Heterometal-organic frameworks as highly sensitive and highly selective luminescent probes to detect $\mathrm{I}(-)$ ions in aqueous solutions. Chem. Commun. 2015, 51, 3985-3988. [CrossRef] [PubMed]

81. Liu, W.; Wang, Y.; Bai, Z.; Li, Y.; Wang, Y.; Chen, L.; Xu, L.; Diwu, J.; Chai, Z.; Wang, S. Hydrolytically Stable Luminescent Cationic Metal Organic Framework for Highly Sensitive and Selective Sensing of Chromate Anions in Natural Water Systems. ACS Appl. Mater. Interfaces 2017, 9, 16448-16457. [CrossRef] [PubMed]

82. Thompson, C.M.; Kirman, C.R.; Proctor, D.M.; Haws, L.C.; Suh, M.; Hays, S.M.; Hixon, J.G.; Harris, M.A. A chronic oral reference dose for hexavalent chromium-induced intestinal cancer. J. Appl. Toxicol. 2014, 34, 525-536. [CrossRef] [PubMed]

83. Zhang, C.; Sun, L.; Yan, Y.; Shi, H.; Wang, B.; Liang, Z.; Li, J. A novel photo- and hydrochromic europium metal-organic framework with good anion sensing properties. J. Mater. Chem. C 2017, 5, 8999-9004. [CrossRef]

84. Ding, B.; Liu, S.X.; Cheng, Y.; Guo, C.; Wu, X.X.; Guo, J.H.; Liu, Y.Y.; Li, Y. Heterometallic Alkaline Earth-Lanthanide $\mathrm{Ba}^{\mathrm{II}}$-La ${ }^{\mathrm{III}}$ Microporous Metal-Organic Framework as Bifunctional Luminescent Probes of $\mathrm{Al}^{3+}$ and $\mathrm{MnO}_{4}{ }^{-}$. Inorg. Chem. 2016, 55, 4391-4402. [CrossRef] [PubMed]

85. Zhao, D.; Wan, X.; Song, H.; Hao, L.; Su, Y.; Lv, Y. Metal-organic frameworks (MOFs) combined with ZnO quantum dots as a fluorescent sensing platform for phosphate. Sens. Actuators B 2014, 197, 50-57. [CrossRef] 
86. Xu, H.; Xiao, Y.; Rao, X.; Dou, Z.; Li, W.; Cui, Y.; Wang, Z.; Qian, G. A metal-organic framework for selectively sensing of $\mathrm{PO}_{4}{ }^{3-}$ anion in aqueous solution. J. Alloys Compd. 2011, 509, 2552-2554. [CrossRef]

87. Xu, H.; Cao, C.S.; Zhao, B. A water-stable lanthanide-organic framework as a recyclable luminescent probe for detecting pollutant phosphorus anions. Chem. Commun. 2015, 51, 10280-10283. [CrossRef] [PubMed]

88. El Sayed, S.; Pascual, L.; Licchelli, M.; Martinez-Manez, R.; Gil, S.; Costero, A.M.; Sancenon, F. Chromogenic Detection of Aqueous Formaldehyde Using Functionalized Silica Nanoparticles. ACS Appl. Mater. Interfaces 2016, 8, 14318-14322. [CrossRef] [PubMed]

89. Li, C.; Huang, J.; Zhu, H.; Liu, L.; Feng, Y.; Hu, G.; Yu, X. Dual-emitting fluorescence of Eu/Zr-MOF for ratiometric sensing formaldehyde. Sens. Actuators B 2017, 253, 275-282. [CrossRef]

90. Wang, Y.; Zhang, G.; Zhang, F.; Chu, T.; Yang, Y. A novel lanthanide MOF thin film: The highly performance self-calibrating luminescent sensor for detecting formaldehyde as an illegal preservative in aquatic product. Sens. Actuators B 2017, 251, 667-673. [CrossRef]

91. Dunning, S.G.; Nuñez, A.J.; Moore, M.D.; Steiner, A.; Lynch, V.M.; Sessler, J.L.; Holliday, B.J.; Humphrey, S.M. A Sensor for Trace $\mathrm{H}_{2} \mathrm{O}$ Detection in $\mathrm{D}_{2} \mathrm{O}$. Chem 2017, 2, 579-589. [CrossRef]

92. Wiberg, K.B. The deuterium isotope effect. Chem. Rev. 1995, 55, 713-743.

93. Wehner, T.; Seuffert, M.T.; Sorg, J.R.; Schneider, M.; Mandel, K.; Sextl, G.; Müller-Buschbaum, K. Composite materials combining multiple luminescent MOFs and superparamagnetic microparticles for ratiometric water detection. J. Mater. Chem. C 2017, 5, 10133-10142. [CrossRef]

94. Guo, Z.; Xu, H.; Su, S.; Cai, J.; Dang, S.; Xiang, S.; Qian, G.; Zhang, H.; O'Keeffe, M.; Chen, B. A robust near infrared luminescent ytterbium metal-organic framework for sensing of small molecules. Chem. Commun. 2011, 47, 5551-5553. [CrossRef] [PubMed]

95. Ma, J.X.; Huang, X.F.; Song, X.Q.; Liu, W.S. Assembly of framework-isomeric $4 \mathrm{~d}-4 \mathrm{f}$ heterometallic metal-organic frameworks with neutral/anionic micropores and guest-tuned luminescence properties. Chem. Eur. J. 2013, 19, 3590-3595. [CrossRef] [PubMed]

96. Lin, Y.W.; Jian, B.R.; Huang, S.C.; Huang, C.H.; Hsu, K.F. Synthesis and characterization of three ytterbium coordination polymers featuring various cationic species and a luminescence study of a terbium analogue with open channels. Inorg. Chem. 2010, 49, 2316-2324. [CrossRef] [PubMed]

97. Wang, S.; Shan, L.; Fan, Y.; Jia, J.; Xu, J.; Wang, L. Fabrication of Ln-MOFs with color-tunable photoluminescence and sensing for small molecules. J. Solid State Chem. 2017, 245, 132-137. [CrossRef]

98. Wang, L.; Fan, G.; Xu, X.; Chen, D.; Wang, L.; Shi, W.; Cheng, P. Detection of polychlorinated benzenes (persistent organic pollutants) by a luminescent sensor based on a lanthanide metal-organic framework. J. Mater. Chem. A 2017, 5, 5541-5549. [CrossRef]

99. Hu, Z.; Deibert, B.J.; Li, J. Luminescent metal-organic frameworks for chemical sensing and explosive detection. Chem. Soc. Rev. 2014, 43, 5815-5840. [CrossRef] [PubMed]

100. Salinas, Y.; Martinez-Manez, R.; Marcos, M.D.; Sancenon, F.; Costero, A.M.; Parra, M.; Gil, S. Optical chemosensors and reagents to detect explosives. Chem. Soc. Rev. 2012, 41, 1261-1296. [CrossRef] [PubMed]

101. Zhang, S.R.; Du, D.Y.; Qin, J.S.; Bao, S.J.; Li, S.L.; He, W.W.; Lan, Y.Q.; Shen, P.; Su, Z.M. A fluorescent sensor for highly selective detection of nitroaromatic explosives based on a 2D, extremely stable, metal-organic framework. Chem. Eur. J. 2014, 20, 3589-3594. [CrossRef] [PubMed]

102. Pramanik, S.; Zheng, C.; Zhang, X.; Emge, T.J.; Li, J. New microporous metal-organic framework demonstrating unique selectivity for detection of high explosives and aromatic compounds. J. Am. Chem. Soc. 2011, 133, 4153-4155. [CrossRef] [PubMed]

103. Sun, Z.; Li, Y.; Ma, Y.; Li, L. Dual-functional recyclable luminescent sensors based on 2D lanthanide-based metal-organic frameworks for highly sensitive detection of $\mathrm{Fe}^{3+}$ and 2,4-dinitrophenol. Dyes Pigment. 2017, 146, 263-271. [CrossRef]

104. Zhao, S.-N.; Song, X.-Z.; Zhu, M.; Meng, X.; Wu, L.-L.; Song, S.-Y.; Wang, C.; Zhang, H.-J. Highly thermostable lanthanide metal-organic frameworks exhibiting unique selectivity for nitro explosives. RSC Adv. 2015, 5, 93-98. [CrossRef]

105. Zhu, M.; Song, X.Z.; Song, S.Y.; Zhao, S.N.; Meng, X.; Wu, L.L.; Wang, C.; Zhang, H.J. A TemperatureResponsive Smart Europium Metal-Organic Framework Switch for Reversible Capture and Release of Intrinsic $\mathrm{Eu}^{3+}$ Ions. Adv. Sci. 2015, 2, 1500012. [CrossRef] [PubMed] 
106. Zhao, S.; Hao, X.-M.; Liu, J.-L.; Wu, L.-W.; Wang, H.; Wu, Y.-B.; Yang, D.; Guo, W.-L. Construction of Eu(III)and $\mathrm{Tb}$ (III)-MOFs with photoluminescence for sensing small molecules based on furan-2,5-dicarboxylic acid. J. Solid State Chem. 2017, 255, 76-81. [CrossRef]

107. Song, X.-Z.; Song, S.-Y.; Zhao, S.-N.; Hao, Z.-M.; Zhu, M.; Meng, X.; Wu, L.-L.; Zhang, H.-J. Single-Crystal-to-Single-Crystal Transformation of a Europium(III) Metal-Organic Framework Producing a Multi-responsive Luminescent Sensor. Adv. Funct. Mater. 2014, 24, 4034-4041. [CrossRef]

108. Zhang, Y.; Yuan, S.; Day, G.; Wang, X.; Yang, X.; Zhou, H.-C. Luminescent sensors based on metal-organic frameworks. Coord. Chem. Rev. 2018, 354, 28-45. [CrossRef]

109. Dou, Z.; Yu, J.; Cui, Y.; Yang, Y.; Wang, Z.; Yang, D.; Qian, G. Luminescent metal-organic framework films as highly sensitive and fast-response oxygen sensors. J. Am. Chem. Soc. 2014, 136, 5527-5530. [CrossRef] [PubMed]

110. Li, Y.; Zhang, S.; Song, D. A luminescent metal-organic framework as a turn-on sensor for DMF vapor. Angew. Chem. Int. Ed. 2013, 52, 710-713. [CrossRef] [PubMed]

111. Wu, P.; Zhang, J.; Wang, S.; Zhu, A.; Hou, X. Sensing during in situ growth of Mn-doped ZnS QDs: A phosphorescent sensor for detection of $\mathrm{H}_{2} \mathrm{~S}$ in biological samples. Chem. Eur. J. 2014, 20, 952-956. [CrossRef] [PubMed]

112. Gao, J.; Li, Q.; Wang, C.; Tan, H. Copper (II)-mediated fluorescence of lanthanide coordination polymers doped with carbon dots for ratiometric detection of hydrogen sulfide. Sens. Actuators B 2017, 253, 27-33. [CrossRef]

113. Zheng, X.; Fan, R.; Song, Y.; Wang, A.; Xing, K.; Du, X.; Wang, P.; Yang, Y. A highly sensitive turn-on ratiometric luminescent probe based on postsynthetic modification of $\mathrm{Tb}^{3+} @ \mathrm{Cu}-\mathrm{MOF}$ for $\mathrm{H}_{2} \mathrm{~S}$ detection. J. Mater. Chem. C 2017, 5, 9943-9951. [CrossRef]

114. Gao, Y.; Jing, P.; Yan, N.; Hilbers, M.; Zhang, H.; Rothenberg, G.; Tanase, S. Dual-mode humidity detection using a lanthanide-based metal-organic framework: Towards multifunctional humidity sensors. Chem. Commun. 2017, 53, 4465-4468. [CrossRef] [PubMed]

115. Han, J.; Burgess, K. Fluorescent Indicators for Intracellular pH. Chem. Rev. 2010, 110, 2709-2728. [CrossRef] [PubMed]

116. Chen, X.; Pradhan, T.; Wang, F.; Kim, J.S.; Yoon, J. Fluorescent chemosensors based on spiroring-opening of xanthenes and related derivatives. Chem. Rev. 2012, 112, 1910-1956. [CrossRef] [PubMed]

117. Qi, Z.; Chen, Y. Charge-transfer-based terbium MOF nanoparticles as fluorescent $\mathrm{pH}$ sensor for extreme acidity. Biosens. Bioelectron. 2017, 87, 236-241. [CrossRef] [PubMed]

118. Dimitriev, O.P.; Kislyuk, V.V. Processes of molecular association and excimeric emission in protonated N,N-dimethylformamide. Spectrochim. Acta Part A 2007, 68, 29-35. [CrossRef] [PubMed]

119. Zhang, X.; Jiang, K.; He, H.; Yue, D.; Zhao, D.; Cui, Y.; Yang, Y.; Qian, G. A stable lanthanide-functionalized nanoscale metal-organic framework as a fluorescent probe for pH. Sens. Actuators B 2018, 254, 1069-1077. [CrossRef]

120. Xia, T.; Zhu, F.; Jiang, K.; Cui, Y.; Yang, Y.; Qian, G. A luminescent ratiometric pH sensor based on a nanoscale and biocompatible Eu/Tb-mixed MOF. Dalton Trans. 2017, 46, 7549-7555. [CrossRef] [PubMed]

121. Zhao, S.-N.; Li, L.-J.; Song, X.-Z.; Zhu, M.; Hao, Z.-M.; Meng, X.; Wu, L.-L.; Feng, J.; Song, S.-Y.; Wang, C.; et al. Lanthanide Ion Codoped Emitters for Tailoring Emission Trajectory and Temperature Sensing. Adv. Funct. Mater. 2015, 25, 1463-1469. [CrossRef]

122. Cui, Y.; Zhu, F.; Chen, B.; Qian, G. Metal-organic frameworks for luminescence thermometry. Chem. Commun. 2015, 51, 7420-7431. [CrossRef] [PubMed]

123. Lian, X.; Zhao, D.; Cui, Y.; Yang, Y.; Qian, G. A near infrared luminescent metal-organic framework for temperature sensing in the physiological range. Chem. Commun. 2015, 51, 17676-17679. [CrossRef] [PubMed]

124. Cui, Y.; Song, R.; Yu, J.; Liu, M.; Wang, Z.; Wu, C.; Yang, Y.; Wang, Z.; Chen, B.; Qian, G. Dual-emitting MOF supersetdye composite for ratiometric temperature sensing. Adv. Mater. 2015, 27, 1420-1425. [CrossRef] [PubMed]

125. Taokaenchan, N.; Tangkuaram, T.; Pookmanee, P.; Phaisansuthichol, S.; Kuimalee, S.; Satienperakul, S. Enhanced electrogenerated chemiluminescence of tris(2,2'-bipyridyl)ruthenium(II) system by L-cysteinecapped CdTe quantum dots and its application for the determination of nitrofuran antibiotics. Biosens. Bioelectron. 2015, 66, 231-237. [CrossRef] [PubMed] 
126. Zhang, F.; Yao, H.; Chu, T.; Zhang, G.; Wang, Y.; Yang, Y. A Lanthanide MOF Thin-Film Fixed with $\mathrm{Co}_{3} \mathrm{O}_{4}$ Nano-Anchors as a Highly Efficient Luminescent Sensor for Nitrofuran Antibiotics. Chem. Eur. J. 2017, 23, 10293-10300. [CrossRef] [PubMed]

127. Gao, Y.; Yu, G.; Liu, K.; Wang, B. Luminescent mixed-crystal Ln-MOF thin film for the recognition and detection of pharmaceuticals. Sens. Actuators B 2018, 257, 931-935. [CrossRef]

128. Hao, J.N.; Xu, X.Y.; Lian, X.; Zhang, C.; Yan, B. A Luminescent 3d-4f-4d MOF Nanoprobe as a Diagnosis Platform for Human Occupational Exposure to Vinyl Chloride Carcinogen. Inorg. Chem. 2017, 56, 11176-11183. [CrossRef] [PubMed]

(C) 2018 by the authors. Licensee MDPI, Basel, Switzerland. This article is an open access article distributed under the terms and conditions of the Creative Commons Attribution (CC BY) license (http://creativecommons.org/licenses/by/4.0/). 